\title{
A Competing Risks Dynamic Hazard Approach to Investigate the Insolvency Outcomes of Property-Casualty Insurers
}

\author{
Huong Dang \\ Department of Economics and Finance, University of Canterbury, Private Bag 4800, \\ Christchurch 8140, New Zealand. \\ E-mail: huong.dang@canterbury.ac.nz
}

This study applies a competing risks approach and an event time dynamic estimation framework to identify the characteristics underlying different insolvency resolutions incurred to U.S. property-casualty insurers during 1998-2010. The estimated hazard model relates the time-varying probability of a specific insolvency outcome to insurers' characteristics and macroeconomic conditions. The study finds that (i) the hazards for different insolvency outcomes are neither equal nor proportionate; (ii) the model for generic insolvency events and the models for outcome-specific insolvency events feature different significant factors, which are not due to random variations; and (iii) the outcomespecific insolvency models exhibit better forecast performance than the generic insolvency model within a five-year forecast horizon. The results of the study provide regulators with early warnings of financial distress, aid them in prioritising troubled insurers and identifying the areas most likely to reveal material problems, and inform about the interventions that should be taken under specific circumstances.

The Geneva Papers (2014) 39, 42-76. doi:10.1057/gpp.2013.13

Keywords: property-casualty insurer; insurance insolvency; competing risks; survival analysis; time-varying covariates; Brier score

Article submitted 16 October 2011; accepted 18 March 2013; published online 29 May 2013

\section{Introduction}

Resolution costs incurred for insolvent property-casualty (PC) insurers have significantly exceeded the costs incurred for other failed financial institutions of comparable size. ${ }^{1}$ However, insolvency costs can be avoided or minimised by the early detection of financially troubled insurers and by effective regulatory interventions.

State insurance regulators in the U.S. may take either regulatory action to prevent a distressed insurer from becoming insolvent or delinquency proceedings with the aim of conserving, rehabilitating or liquidating the troubled insurer. ${ }^{2}$ If preventative regulatory actions are taken too late and an insurer becomes severely distressed or insolvent, the insurer will be placed into receivership. For regulators, in contemplating

\footnotetext{
${ }^{1}$ Grace et al. (2003).

${ }^{2}$ Klein and Barth (1995).
} 
the course of regulatory actions to be taken against a distressed insurer, it is useful to have a model that (i) identifies how cases similar to the one being considered were treated under a specific set of circumstances and (ii) enables them to take the most appropriate option in a timely manner.

Insurance studies have, to date, focused on the insolvency/solvency dichotomy and treated multiple insolvency outcomes as equivalent. A qualitative response static model has been widely employed in the insurance literature to identify the determinants of a generic insolvency event. ${ }^{3}$ The models employing a static estimation approach are not ideal for modelling credit events for several reasons. ${ }^{4}$ First, they use cross-sectional data and take into account the value of a variable at a single instant of time. Since the time data observed are chosen arbitrarily, the estimates are subject to selection bias (p. 102). ${ }^{5}$ Second, the static models fail to allow for the fact that insurers' financial conditions deteriorate as they approach insolvency. ${ }^{6}$ The static models therefore explain little about the dynamics of financial distress and do not shed light on the underlying processes that determine the duration of time until an insolvency event occurs. Third, the static models such as logit/probit do not produce a forecast as a function of time and fail to give any insight into when insolvency will take place. These models, therefore, cannot provide regulators with a warning of insolvency with a sufficient lead time. ${ }^{4}$ From a regulator's perspective, this is a serious limitation because intervention should occur before an insurer has reached such an advanced stage of distress that its failure is inevitable. Insolvencies frequently occur because of bad timing rather than as a result of poor financial conditions. ${ }^{2}$

The need to explore time-varying risk factors associated with multiple insolvency states and to generate probability survival estimates that vary across forecast horizons has not been addressed in the insurance literature. This study attempts to fill this gap and answers the following four questions: (i) Is it reasonable to treat all types of insolvency events as equivalent? (ii) Are the leading causes for outcome-specific insolvency events and for a generic insolvency event the same? (iii) If the underlying determinants differ, are the differences the results of random variations? and (iv) Do the models for outcome-specific events exhibit better forecast performance out-ofsample than the model for generic events?

The study answers the above questions by examining the probable duration of each PC insurer in the study. How likely is it that by time $t$ (in the set $t=1$ to $T$ ) there will be an insolvency event of type $s$ ? This probability can be derived from a survivor function $S(s, t)$ which can be estimated using a type-specific Cox's hazard model, ${ }^{7}$ where $S(s, t)=P(s, T>t)$ and $P(s, T>t)$ is the probability that the insolvency outcome $s$ will occur at time $T$ after a duration of time $t$.

\footnotetext{
${ }^{3}$ See, for example, Cummins et al. (1995), Browne and Hoyt (1995), Barniv and Hathorn (1997), Barniv et al. (1999), Sharpe and Stadnik (2007).

${ }^{4}$ LeClere (2000).

${ }^{5}$ Shumway (2001).

${ }^{6}$ BarNiv and McDonald (1992).

${ }^{7}$ Cox (1972).
} 
Static and dynamic hazard models have been employed in Lee and Urrutia $^{8}$ and Kim et al. ${ }^{9}$ respectively. These two insurance insolvency studies differ from this study in several major ways. First, Kim et al. ${ }^{9}$ and Lee and Urrutia $^{8}$ treated different insolvency outcomes as equivalent. The literature on corporate failures emphasises the need to distinguish between multiple states of financial distress typically faced in reality by companies. ${ }^{10}$ A model that accommodates multiple financial distress states provides an opportunity to investigate the impact of key risk factors across distress scenarios. ${ }^{11}$ I am of the view that an administrative supervision event is likely to have quite different determinants than a liquidation order. Lumping different insolvency events into the same analysis clouds the results for specific insolvency outcomes and results in misspecification. Second, Kim et al. and Lee and Urrutia formed small matched-pair samples of insolvent and solvent insurers. Models estimated with relatively small paired samples result in potential bias, a sub-optimal set of significant variables, and tend not to perform very well when applied against a much larger group of companies, most of whom are not insolvent. ${ }^{12}$ Third, Kim et al. and Lee and Urrutia did not construct time-varying survival estimates out-of-sample and were therefore unable to assess the predictive performance of the estimated models at different forecast horizons.

This study extends the literature as follows. First, I use a much larger sample of PC insurers than previous studies, and develop Cox's dynamic hazard models that resolve some of the limitations of the widely-used static logit/probit model. The Cox's hazard model $^{7}$ is considered the pre-eminent method in modelling credit events. ${ }^{13}$ The estimated Cox's dynamic hazard models employ time-varying covariates and control for the changes in the financial characteristics of firms and the development of the macroeconomic environment over time. Second, I apply an event-time competing risks approach and treat different insolvency outcomes as distinct. As far as I am aware, this study is the first attempt to apply a competing risks dynamic hazard approach to identify the significant factors that impact on the probability of a PC insurer being dealt with under different regulatory options. Third, while the estimation and forecasting technology for the Cox's proportional hazard model (with time-fixed covariates) is readily available, this is not the case for the Cox's dynamic hazard model (with time-varying covariates). I adapt the method of computation to the complicated setting of the model, which combines innovative features of a competing risks approach, time-varying risk factors and an event time dynamic estimation framework. The study overcomes computational challenges in generating time-varying probability survival estimates when the proportionality of the conventional Cox's hazard model ${ }^{7}$

${ }^{8}$ Lee and Urrutia (1996).

${ }^{9}$ Kim et al. (1995).

${ }^{10}$ See, for example, Lau (1987), Schary (1991), Harhoff et al. (1998), Wheelock and Wilson (2000), Koeke (2002), Prantl (2003), Dyrberg (2004), Hensher et al. (2007), Bhattacharjee et al. (2009), He et al. (2010), Chancharat et al. (2010), Pérez et al. (2010).

${ }^{11}$ Hensher and Jones (2007).

12 BarNiv and McDonald (1992); Klein and Barth (1995); Carson and Hoyt (2003).

${ }^{13}$ For a discussion of the attractive features of the Cox's hazard model, see Allison (1984, 1995) and LeClere (2000). 
breaks down. The time structure of probability survival estimates may assist regulators when examining the survival profile of an insurer and in detecting distressed insurers with a sufficient lead time. ${ }^{14}$ Finally, the study enriches the literature on the framework for evaluating probability estimates by employing the Brier score, ${ }^{15} \mathrm{a}$ popular measure for ex post evaluation of meteorological forecasts. ${ }^{16}$ The Brier score has been applied in several financial studies, such as Samuelson and Rosenthal, ${ }^{17}$ Bessler and Ruffley, ${ }^{18}$ Yao et al., ${ }^{19}$ Grunert et al. ${ }^{20}$ Unlike Type I and Type II errors, the Brier score does not require the selection of a cut-off point, as it measures the mean squared error of the probability forecasts assigned to all holdout insurers. The Brier score provides a better measure of forecast performance than the ROC curve applied in previous insurance studies, as the score captures both the discrimination and the calibration abilities of the estimated model. ${ }^{21}$ The Brier score can also be decomposed into forecast components and provides feedback to improve the estimated model. ${ }^{22}$ Johnstone $^{23}$ suggested that the Brier score is superior to categorical measures in accurately assessing the predictive power of probability forecasts.

This study develops dynamic hazard models to establish the important factors that influence the probability of an insurer being placed by its regulator under administrative supervision, conservation/other, rehabilitation and liquidation. It is found that each insolvency outcome has its own hazard that governs the occurrence and the timing of the event. The dynamic hazard models for outcome-specific insolvency events and the dynamic hazard model for generic insolvency events feature different significant risk factors, which are not due to random variations. The outcome-specific models exhibit better predictive accuracy than the generic model and flag holdout insurers that subsequently failed as potential "targets" for specific insolvency events. The implication is that different insolvency outcomes are distinct phenomenon and should not be treated as equivalent, as in previous studies. The

${ }^{14}$ Whalen (1991, p. 21) found that Cox's proportional hazard model "identified failed and healthy banks with a high degree of accuracy" and "flagged a large proportion of banks that subsequently failed as potential failures in periods prior to their actual demise".

15 Brier (1950).

${ }^{16}$ Murphy and Winkler (1977); Winkler et al. (1996).

${ }^{17}$ Samuelson and Rosenthal (1986).

${ }^{18}$ Bessler and Ruffley (2004).

${ }^{19}$ Yao et al. (2005).

${ }^{20}$ Grunert et al. (2005).

${ }^{21}$ Type I/Type II errors and ROC curve have been widely employed in previous insurance insolvency studies such as Trieschmann and Pinches (1973), BarNiv and McDonald (1992), Cummins et al. (1995), Barniv and Hathorn (1997), Sharpe and Stadnik (2007). However, these measures suffer from several problems. For Type I/ Type II errors, the choice of an arbitrary cut-off score may not be relevant to the research design and may bias the correct classification (BarNiv and McDonald, 1992, pp. 545-546). The ROC curve, while considering the entire range of possible cut-off points, merely captures the discrimination power of the estimated model. Furthermore, both Type I/Type II errors and the ROC curve do not offer the possibility to examine the characteristics of probability estimates and to analyse the sources of forecast errors.

22 Sander (1963); Murphy (1973); Yates (1982).

23 Johnstone (2002). 
results of this study provide regulators with early warnings of financial distress and the information required to take appropriate regulatory actions.

The remainder of this paper is structured as follows. The next section discusses financial insolvency outcomes, the subsequent section describes the samples and variables employed, the latter section presents the estimation and validation methods, the penultimate section summarises the results and the final section puts forward the key findings, implications and limitations of the study.

\section{Financial insolvency outcomes}

\section{Financial insolvency outcomes}

The insolvency data used were provided by A.M. Best. To classify an insurer as either insolvent or solvent, the study follows A.M. Best ${ }^{24}$ and the previous insurance insolvency studies that utilised A.M. Best's data. ${ }^{25}$ An insurer is categorised as insolvent "as of the first official regulatory action" taken against it by its domiciliary state's insurance department, where its ability to undertake normal insurance operations is negatively affected, its capital and surplus are inadequate to meet legal requirements, and/or its overall financial state has triggered regulatory concern $^{26}$ (p. 8). ${ }^{27}$

The type, timing and degree of regulatory action depend on the circumstances of each case and the particular jurisdiction's laws and regulations applying to an insurer (p. 24). ${ }^{28}$ A state regulator may take preventive action by way of administrative supervision, or corrective action by placing the insurer in receivership. Preventive action does not require a court order, but corrective action does. From a legal perspective, different insolvency resolutions dictate the extent to which a state regulator controls a troubled insurer.

Under the National Association of Insurance Commissioners (NAIC) Administrative Supervision Model Act, ${ }^{29}$ a state insurance regulator may place a licensed insurer in administrative supervision if: (i) continuation of the insurer's business would result in an increased risk of loss to its insured or be risky for the public, (ii) the insurer has acted beyond the powers granted to it under its certificate of authority and

${ }^{24}$ A.M. Best $(2009,2010,2011)$.

${ }^{25}$ For example, Browne and Hoyt (1995); Grace et al. (1998); Larson (1998); Grace et al. (2003).

${ }^{26}$ A.M. Best uses the term "financially impaired" to refer to insurers that experienced the first regulatory intervention from its domiciliary state's insurance department. These include insurers operating in a financially hazardous manner (impaired) and insurers with insufficient assets to pay their policy claims (insolvent). Prior insurance insolvency studies, which employed the same data from A.M. Best and examined the same events as this study, used the term "insolvent insurers" to refer to "financially impaired insurers" defined by A.M. Best. To be consistent with the prior literature, in this paper I use the term "insolvent insurers" or "distressed insurers" to encompass insurers with negative net worth and insurers that were sufficiently impaired to prompt regulatory intervention.

27 A.M. Best (2010).

28 Johnson et al. (2005).

${ }^{29}$ National Association of Insurance Commissioners, Model Laws, Regulations and Guidelines, v.3, Administrative Supervision Model Act § 3.A (Model 558). 
relevant statute or it has failed to fully comply with the relevant state insurance law, (iii) its business is being undertaken in a fraudulent manner, or (iv) the insurer consents (p. 41). ${ }^{30}$

During supervision, the business of the insurer is overseen by an administrative supervisor, but the insurer's management stays in control (p. 6). ${ }^{31}$ A supervised insurer is generally required to take specific action, and/or to obtain prior approval for all inter-company transactions, reinsurance transactions, major investments, staffing changes and revision to commission scales. ${ }^{32}$ The aim is to monitor and modify the actions of an insurer that may be heading towards rehabilitation or liquidation, with the hope of restoring it to the market as a viable business (p. 6). ${ }^{31}$ If supervision is too late or ineffective, the regulator can take further enforcement action by making a petition to the relevant state court to place it in receivership.

Proceedings for receivership are usually taken against a distressed insurer in the state of incorporation. ${ }^{33}$ Each state has its own insurer insolvency law, but most have enacted the Insurers Rehabilitation and Liquidation Model Act, superseded in 2005 by the NAIC Insurer Receivership Model Act, or the Uniform Insurer's Liquidation Act (p. 2). ${ }^{31}$ The structure and subject matter of insurance statutes in various states are similar.

A state regulator may make a petition to the state's court for a conservation order against a domestic insurer. A receiver is appointed to take over the operations of the insurer, control and examine the assets, books, records and business premises, and to decide whether the insurer can be rehabilitated. A conservation order gives the regulator time to consider alternative regulatory actions and to decide whether to: (i) release the insurer from conservation to normal operations with private management, (ii) place the insurer into rehabilitation, or (iii) place the insurer into liquidation (p. 6). ${ }^{31}$

A state regulator may petition the court to place an insurer into rehabilitation when its continued viability is regarded as possible (p. 2). ${ }^{31}$ The rehabilitation order may limit or bar the insurer from certain investments, prohibit it from writing new business or renewing business, or restrict the amount and type of new business that may be written. The regulator in the insurer's domiciliary state will be appointed the rehabilitator, and will take over the operational authority from the insurer's management, administer its assets and control its business with the aim of reforming or revitalising it (p. 24). ${ }^{28}$

Under the NAIC Insurer Receivership Model Act, an insurer may be placed into rehabilitation on various grounds ${ }^{34}$ including: (i) impairment, an unsound financial position, or imminent insolvency; (ii) the maintenance of unsound or improper business policies, methods or practices; (iii) the continuation of its business will be hazardous to policyholders, creditors or the public; (iv) the whole of, or substantially the whole of, its assets have been transferred without the permission of the domiciliary state regulator;

${ }^{30}$ Dembeck (2008).

${ }^{31}$ Mayer et al. (2011).

${ }^{32}$ Liskov and Mros (2009); Mayer et al. (2011, p. 6).

${ }^{33}$ www.i-site.naic.org/help/html/GRID\%20FAQs.html\#insolvency, accessed 15 September 2010.

${ }^{34}$ National Association of Insurance Commissioners, Model Laws, Regulations and Guidelines, v.3, Insurer Receivership Model Act $\S \S 207 . B$ and 207.I (Model 555). 
(v) it is under the control of an untrustworthy or dishonest person; or (vi) it has violated its charter, insurance department orders or other similar requirements. ${ }^{35}$

The rehabilitator will submit a plan of rehabilitation to the state court for approval and "anything that will restructure, revitalise or reform the insurer can be proposed in a plan" (p. 20). ${ }^{36}$ The policyholders and creditors of a rehabilitated insurer have no voting rights with regard to a rehabilitation plan which, however, must be equitable to both policyholders and creditors, and provide for, at minimum, what the policyholders would have received in a liquidation (pp. 3-4). ${ }^{31}$ Upon approval by the court, the rehabilitator will take remedial action, for example, reorganisation, consolidation, or a merger, with the aim of revitalising the insurer and returning it to viability. The process may last several years and may ultimately result in control being restored to the insurer. ${ }^{31}$

A state regulator may petition the court for a liquidation order if the viability of an insurer is doubtful and/or rehabilitation is not realistic. ${ }^{37}$ The regulator, as liquidator, will be authorised to control all aspects of the insurer's business, under the supervision of the court. Liquidation normally involves seizing and controlling the insurer's assets, determining its liabilities, and distributing the assets under the supervision of the court, according to a statutory priority distribution scheme (p. 24). ${ }^{28}$ The claim priority rule protects policyholders, their beneficiaries and claimants. ${ }^{1}$ Policyholders are to be paid in full before other creditors receive any sort of distribution. ${ }^{38}$ If the assets of a liquidated insurer are insufficient to cover the claims of its policyholders, beneficiaries and third-party claimants, the state's guaranty fund is the source of last resort to provide coverage for certain types of claims up to certain legally mandated limits (p. 25). ${ }^{28,39}$

An insurer is placed in liquidation for broadly the same reasons as those underlying rehabilitation proceedings. If the insurer is already in rehabilitation the receiver may need to show that further rehabilitation efforts would significantly increase the risk of loss to policyholders, creditors or the public, or would be futile (p. 5). ${ }^{31}$ The major difference between a rehabilitation and a liquidation is that the aim of rehabilitation is to try to eliminate the factors that led to the need for rehabilitation and restore it to viability (p. 8) ${ }^{40}$ whereas the aim of a liquidation is to wind-up the company, without any attempt to keep it in business (p. 5). ${ }^{31}$

Different regulatory actions discussed above impact differently on an insurer's management, policyholders, creditors, reinsurers and other insurers incumbent in the same state. The distressed insurer's management remains in control of the business if it is placed under supervision, but lose operational authority if it is placed into receivership. The policyholders of a rehabilitated insurer may not receive full settlement,

\footnotetext{
${ }^{35}$ Vacca (2007); Mayer et al. (2011, p. 3).

${ }^{36}$ NAIC (2009).

${ }^{37}$ Liskov and Mros (2009); Mayer et al. (2011, p. 4).

${ }^{38}$ Liskov and Mros (2009).

${ }^{39}$ Guaranty funds are accumulated via assessments on solvent insurers licensed to do business in the state. Assessments are based on members premiums written in the covered lines of business in the state and are subject to an annual cap (Vacca, 2007).

${ }^{40}$ Bickford (2004).
} 
or payments may be spread over a period of time. Similarly, the reinsurers and the general creditors of a rehabilitated insurer may not receive any payment if this is necessary to rescue and revitalise the insurer. Incumbent insurers in good financial health may have to take responsibility for policies written by a rehabilitated insurer if requested by the relevant state court. ${ }^{41}$ The shareholders of a liquidated stock insurer may lose their investments or may receive negligible residual capital after all policyholders, government claims and general creditors have been paid.

The uncertainties associated with each distress state have significant implications for stakeholder incentives. Managers may wish to move the distressed company towards a preferred outcome, aiming to extend their time in control and/or minimise the consequences of losing their jobs. Conversely, regulators tend to use liquidation proceedings to trigger guaranty association coverage for policyholders and claimants, instead of producing plans that will reduce the losses to lower priority claimants ( $\mathrm{p}$. 9). ${ }^{1}$ As guaranty associations are triggered by the liquidation of an insolvent insurer, the state's member insurers will want to know the likelihood of a liquidation outcome. The policyholders, general creditors, reinsurers and shareholders of a distressed insurer will want to predict the probability and the timing of a likely receivership outcome as well as their payoff under each scenario. This emphasises the need to consider multiple insolvency scenarios and to identify the excessive risk-taking behaviours that are typical to a specific insolvency outcome.

Should insurers experiencing different insolvency outcomes be regarded as identical, as in previous studies on insurance insolvency? I am of the view that different insolvency outcomes follow different processes that govern the occurrence and the timing of the events, and that different insolvency states are associated with different underlying risk factors.

\section{Competing risks}

Regulatory interventions can be progressive and a distressed insurer may experience a spectrum of financial insolvency states before being liquidated. ${ }^{42}$ This is the natural outcome of recurrent insolvency events. However, a distressed insurer cannot simultaneously be in more than one insolvency mode at any point in time. The occurrence of one insolvency state removes a financially distressed insurer from the risk of all other insolvency states at that point in time. Thus, the different insolvency outcomes can be treated as competing risks.

The insolvency data used in this study include information on the first regulatory action taken by a state regulator against a domestic insurer. Any regulatory actions subsequent to the first regulatory intervention fall outside the scope of this study. As only the first regulatory action is recorded and examined, each distressed insurer contributes only one insolvency event to the study. The final data set includes 195 insolvency events initially categorised into five manners (outcomes), of which supervision, conservation, rehabilitation, liquidation and other events (involuntary

\footnotetext{
${ }^{41}$ Liskov and Mros (2009); Mayer et al. (2011, p. 3).

42 Grace et al. (2003); Klein (2009); Mayer et al. (2011).
} 
Table 1 Equal hazard test statistics

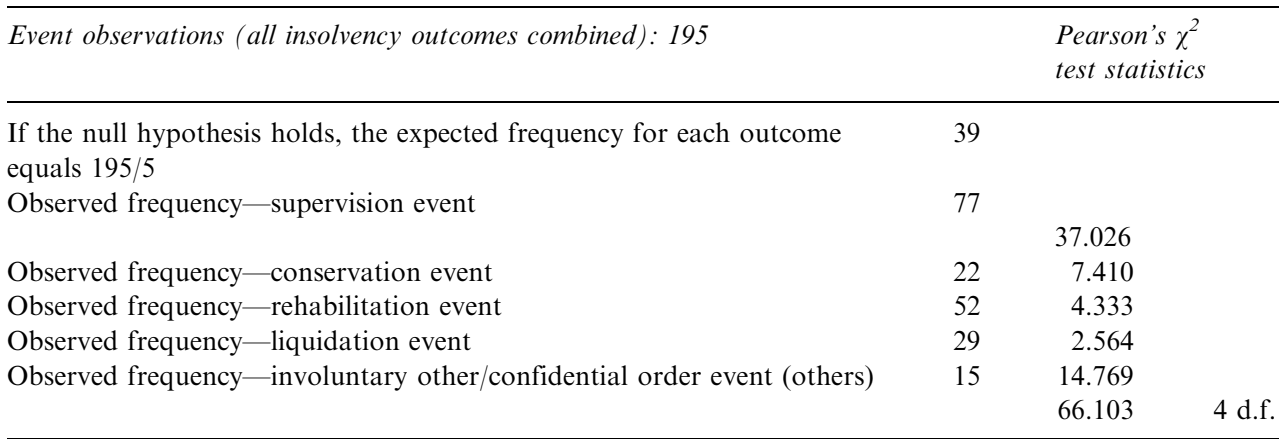

This table presents the statistics of the Pearson's $\chi^{2}$ test against the null hypothesis that the hazard functions are the same for the five insolvency outcomes observed in the study. The Pearson's $\chi^{2}$ statistics yields a value of 66.1 and is statistically significant at better than the 1 per cent level.

other/confidential order) respectively contribute 77, 22, 52, 29 and 15 observations. The observed frequencies of the five event types suggest that supervision and rehabilitation are more likely to occur than conservation, liquidation and other events. This is not surprising given the nature of insolvency resolutions discussed in the previous section and the regulators' goal to maintain a smooth functioning market.

For each observed insolvency outcome, there is a separate hazard function, namely a type-specific insolvency hazard, which can be interpreted as the number of insolvency events of that type (outcome) per one unit time interval (p. 186). ${ }^{43}$ To lay the foundation for the case that different insolvency states follow different processes, it is necessary to conduct a formal statistic test for equal hazards for the five observed insolvency outcomes. If the null hypothesis of equal hazards is correct, the expected frequencies of the five insolvency types should be equal in any time interval (p. 190). ${ }^{43}$ I calculate the Pearson's $\chi^{2}$ statistics for equal hazards as shown in Table 1 . The test yields a value of 66.1 with four degrees of freedom, confirming that the observed frequency distribution is statistically different from the expected frequency distribution. The null hypothesis of equal hazards for observed insolvency outcomes can therefore be rejected at 1 per cent significance level.

Testing for hazard equality is a natural preliminary step to testing for hazard proportionality. If the observed insolvency outcomes have different hazards and their hazards are not proportional in any time interval, then they follow different processes and cannot be treated identically as they have been in previous insurance studies. Thus, the next question to be addressed is: Are the hazards proportional? That is, if the hazard for a non-liquidation event changes with time, will the hazard for a liquidation event change by a proportional amount?

\footnotetext{
${ }^{43}$ Allison (1995).
} 
Liquidation candidates typically exhibit rapid deterioration in credit quality and tend to be weeded out by the regulator in a drastic and quick manner rather than through gradual, mild steps. However, if an insurer is not so severely distressed that it needs to be liquidated quickly, the regulator tends to give it more leeway in the hope it will show good recovery and rebound strongly later. If such an insurer fails to substantially improve its credit quality it will exhibit, as time passes, a greater likelihood of failure and a faster approach to a non-liquidation insolvency state. Thus, I hypothesise that the hazards for non-liquidation insolvency events increase more rapidly with time than the hazard for liquidation events.

To test the null hypothesis of proportional hazards for the observed insolvency outcomes, the following multinomial logit model was estimated. ${ }^{44}$

$$
\log \left[h_{j}(t)\right]=\alpha_{0}(t)+\alpha_{j}+\beta_{j} t
$$

where $j=1,2,3$, respectively, indicates the contrast between a non-liquidation event (a supervision, a conservation/other, ${ }^{45}$ a rehabilitation) and a liquidation event.

$t$ is the survival time (i.e. event time) of an insolvent insurer measured from the time it entered the study until the time it experienced the first regulatory action (a typespecific insolvency outcome). Insurers that did not experience an insolvency event during the study period were excluded from the analysis.

$\log \left[h_{j}(t)\right]$ is the logarithm of the hazard for the contrast between two event types $j$ at time $t$.

$\beta_{j}$ is the survival time coefficient for the contrast between the two event types $j$.

The results of the model estimated as per Eq. (1) are presented in Table 2. Panel A of Table 2 provides the analysis of variance output. Panel B of Table 2 presents the coefficient estimates derived from the maximum likelihood procedure.

Under the proportional hazards hypothesis, the coefficient for survival time $t, \beta_{j}$, will be zero. As shown in Table 2, Panel A, the effect of survival time $t$ is significant at the 1 per cent level, indicating a rejection of the proportional hazards hypothesis. The parameter estimates for survival time $t$ (Table 2, Panel B) show that the $\beta$ coefficients for the contrast between a supervision and a liquidation $\left(\beta_{1}\right)$, a conservation/other and a liquidation $\left(\beta_{2}\right)$, a rehabilitation and a liquidation $\left(\beta_{3}\right)$ are statistically significant. As expected, the hazards for a supervision, a conservation/other and a rehabilitation event increase more rapidly with time than the hazard for a liquidation event. Their ratios increase by $34.47,22.58$ and 46.10 per cent each year, respectively. ${ }^{46}$ The loghazards for the contrast between a non-liquidation insolvency event and a liquidation event therefore diverge non-linearly with time.

This analysis suggests that different insolvency outcomes follow different processes that govern both the occurrence and the timing of the events. Thus, alternative

\footnotetext{
${ }^{44}$ Cox and Oakes (1984).

${ }^{45}$ Owing to its low observed frequency (see Table 1), the fifth category of insolvency state (other or involuntary other/confidential order) is combined with the second type (conservation). This combination makes a conservative assumption that an "other" event should be, at the least, treated as a conservation event, the least serious of the three event types that involves a state court order.

${ }^{46} 100\left(e^{0.3182}-1\right)=34.47 \% ; 100\left(e^{0.2036}-1\right)=22.58 \% ; 100\left(e^{0.3791}-1\right)=46.1 \%$.
} 
Table 2 Proportional hazard test statistics

\begin{tabular}{|c|c|c|c|c|}
\hline Source & \multicolumn{2}{|c|}{ Degrees of freedom } & \multicolumn{2}{|c|}{$\chi^{2}$} \\
\hline \multicolumn{5}{|c|}{ Panel A: Maximum likelihood analysis of variance } \\
\hline Intercept & 3 & & \multirow{2}{*}{\multicolumn{2}{|c|}{$\begin{array}{c}5.17 \\
12.83 * * *\end{array}$}} \\
\hline Survival time $t$ & 3 & & & \\
\hline Parameter estimates & Function number $j$ & Estimate & Standard error & $\chi^{2}$ \\
\hline \multicolumn{5}{|c|}{ Panel B: Analysis of maximum likelihood estimates } \\
\hline \multirow[t]{3}{*}{ Intercept estimate, $\alpha_{j}$} & 1 & -0.2284 & 0.4327 & 0.28 \\
\hline & 2 & -0.4632 & 0.4768 & 0.94 \\
\hline & 3 & $-0.9257 * *$ & 0.4712 & 3.86 \\
\hline \multirow[t]{3}{*}{ Survival time coefficient estimates, $\beta_{j}$} & 1 & $0.3182^{* * *}$ & 0.1102 & 8.34 \\
\hline & 2 & $0.2036^{*}$ & 0.1204 & 2.86 \\
\hline & 3 & $0.3791 * * *$ & 0.1139 & 11.08 \\
\hline
\end{tabular}

$* * * p$-value $\leqslant 1$ per cent, $* * 1$ per cent $<p$-value $\leqslant 5$ per cent, $* 5$ per cent $<p$-value $\leqslant 10$ per cent.

This table presents the results of the multinomial logit model estimated as in Eq. (1) (Cox and Oakes, 1984) for 195 insolvent insurers in the study. Observations that had not experienced an insolvency event were excluded from this test against the null hypothesis that the hazards are proportional for the insolvent outcomes examined (supervision, conservation/other, rehabilitation, liquidation). Panel A provides the analysis of variance output. Panel B presents the survival time coefficient estimates $\left(\beta_{1}, \beta_{2}, \beta_{3}\right)$, derived from the maximum likelihood procedure, for the contrast between a non-liquidation insolvency event (a supervision, a conservation/other, a rehabilitation) vs a liquidation event. Parameter estimates are given first followed by the corresponding $p$-value.

insolvency outcomes should not be treated as identical as has been done in previous insurance studies.

\section{Samples and variables}

\section{Samples}

This study employs a large sample of PC insurers in the U.S. during the period January 1998-June 2010. The insolvency data provided by A.M. Best were matched with firmspecific data obtained from SNL Financial. The reported data set was restricted to include only those insurers for which firm-specific time series data are available. The final data include 2,098 PC insurers, of which 195 (9.3 per cent) were insolvent and 1,903 (90.7 per cent) did not experience any insolvency event during the study period.

To construct estimation and holdout samples, the study adopts the random crosssectional sampling approach applied by the Austrian National Bank (p. 11). ${ }^{47}$ The estimation and the holdout samples, respectively, account for 65 and 35 per cent of observations in the final data set. These samples were randomly constructed, except that the total insolvency rate in the holdout sample is set equal to the total insolvency

${ }^{47}$ Halling and Hayden (2006). 
rate in the estimation sample. Each insurer contributes only one observation to either the estimation or the holdout sample. This random cross-sectional sampling approach allows for a large number of insurers in the at-risk population and provides sufficient historical outcome-specific insolvency data for out-of-sample forecast assessment. ${ }^{48}$

\section{Survival time}

The survival time of an insurer was measured from the time it entered the study until the time it left the study. I hypothesise that insurers heading towards different receivership proceedings (i.e. conservation, rehabilitation, liquidation) exhibit statistically different survival durations, which has implications for regulatory behaviour and incentives. For a receivership candidate, a longer survival time may suggest a regulator's discretionary delay in enforcing appropriate actions before formal proceedings are initiated, whereas a shorter survival time may signal a regulator's willingness to take drastic corrective action and to quickly reveal the insurer's poor financial condition.

State regulators tend to give more leeway to insurers who are heading towards rehabilitation proceedings. This tendency can be attributed to several factors including budgetary constraints and the nature of the rehabilitation proceeding, in which the rehabilitator (state regulator) has broad discretion, without being limited by time, to take corrective actions, subject to oversight by the state court. On the other hand, state regulators tend to exhibit less leniency against distressed insurers who are heading towards a conservation proceeding. As regulators are uncertain about the specific course of regulatory action to be taken to remedy these insurers, they tend to place them into a conservation proceeding quickly, paving the way for a detailed investigation of the insurers' financial conditions and a thorough consideration of appropriate corrective actions.

It is expected that liquidation candidates cling to life for a shorter period of time than non-liquidation prospects. Severely distressed insurers with doubtful continued viability tend to be under the close scrutiny of state regulators and are potential targets for liquidation. Delaying the liquidation of such insurers increases the risk that they "will haemorrhage more money, certain assets may lose value or the cost of certain liabilities could increase" (p. 18). ${ }^{1}$ To prevent losses that would otherwise occur, state regulators tend to be prompt in placing severely distressed insurers into liquidation.

Figure 1 depicts the distribution of the survival times to specific types of insolvency events observed during the study period January 1998-June 2010. The four types of insolvency events show a positively skewed survival time distribution. As hypothesised, the majority of liquidation candidates are short-lived. Rehabilitation candidates display a greater tendency to survive than conservation/other and liquidation prospects.

The descriptive statistics for the survival times of survived, generic insolvent and type-specific insolvent insurers are presented in Table 3. The t-test and the Wilcoxon

\footnotetext{
${ }^{48}$ An alternative approach is to construct time-series estimation/holdout samples. This approach is relevant if regulators want to know whether models estimated on historical data can be used to make predictions (BarNiv and McDonald, 1992, p. 555). However, given the scarcity of observed data for conservation/ other and liquidation events during the last five years of the study (not reported), it would be difficult to calibrate the models for these rare events using a time-series holdout sample.
} 

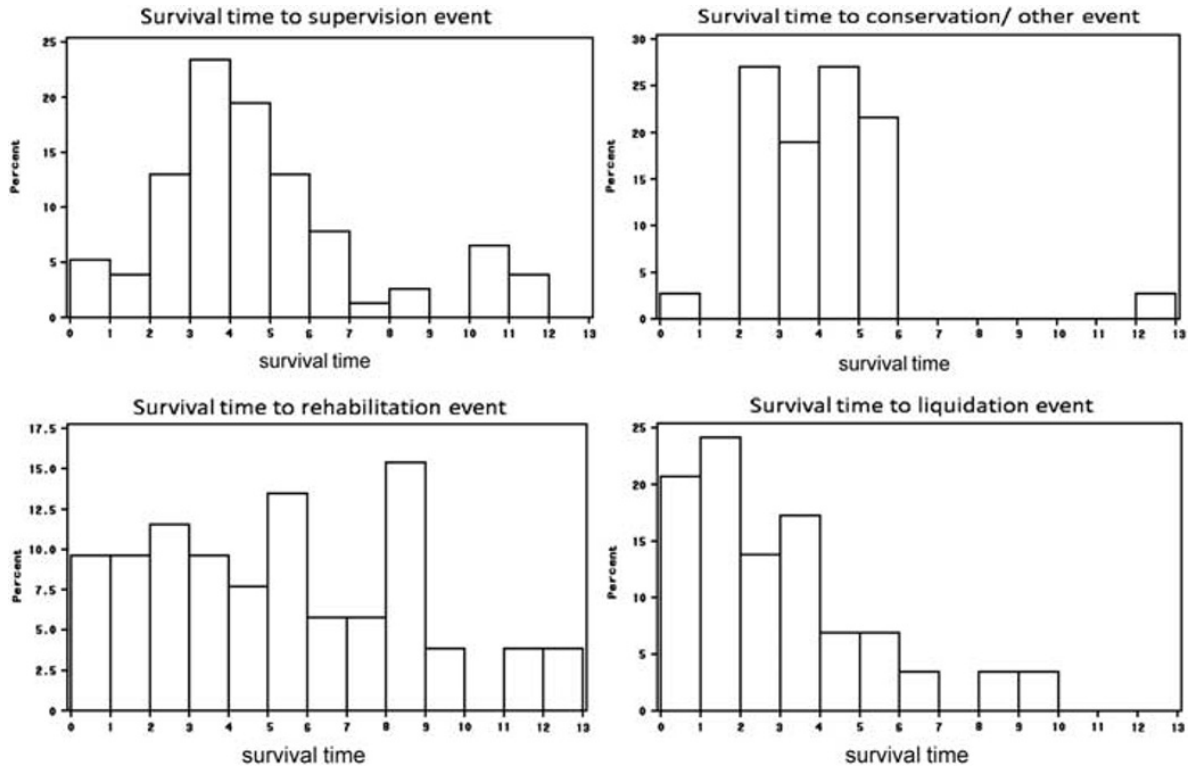

Figure 1. Histogram of the survival time of financially distressed insurers.

Note: This figure depicts the distribution of the time to outcome-specific event (survival time) for financially distressed insurers in the study. The survival time of a distressed insurer was measured from the time it entered the study until the time it experienced the first regulatory action. Of 195 event observations, 77 were supervised, 37 received a conservation order/a confidential order or an involuntary other event, 52 were rehabilitated, and 29 were liquidated.

Table 3 Descriptive statistics of survival time

\begin{tabular}{lcccccrrr}
\hline Firm status & $\begin{array}{c}\text { Number of } \\
\text { observations }\end{array}$ & $\begin{array}{c}\text { Mean } \\
\text { (years) }\end{array}$ & $\begin{array}{c}\text { Median } \\
\text { (years) }\end{array}$ & $\begin{array}{c}\text { Standard } \\
\text { deviation }\end{array}$ & $\begin{array}{c}\text { Minimum } \\
\text { (days) }\end{array}$ & $\begin{array}{c}\text { Maximum } \\
\text { (years) }\end{array}$ & Skewness & Kurtosis \\
\hline Survived & 1,903 & 11.790 & 12.504 & 2.265 & 86 & 12.504 & -3.321 & 10.173 \\
Insolvent & 195 & 4.488 & 4.104 & 2.781 & 7 & 12.236 & 0.960 & 0.606 \\
Supervised & 77 & 4.754 & 4.148 & 2.688 & 155 & 11.962 & 1.160 & 0.949 \\
Conserved/other & 37 & 3.978 & 4.156 & 1.905 & 121 & 12.153 & 2.039 & 8.619 \\
Rehabilitated & 52 & 5.267 & 5.132 & 3.325 & 7 & 12.236 & 0.343 & -0.744 \\
Liquidated & 29 & 3.037 & 2.764 & 2.309 & 153 & 9.066 & 1.134 & 0.928 \\
\hline
\end{tabular}

This table presents the descriptive statistics of the survival time for survived insurers, generic insolvent insurers and type-specific insolvent insurers in the study. Additional analysis (not reported) indicates that the survival times for survived insurers and generic insolvent insurers are statistically different. Similarly, insurers experiencing different insolvency outcomes have statistically different survival times.

test (not reported) indicate that survived and generic insolvent insurers as well as insurers experiencing different insolvency outcomes exhibit statistically different survival times. Rehabilitation candidates, on average, cling to life for longer than other distressed insurers. This suggests that regulators may have foregone dealing with these troubled insurers at an earlier stage. More timely interventions might have increased 
the chance that the problems of these financially distressed insurers could be fixed without resorting to rehabilitation proceedings. On the other hand, candidates for conservation/other events have the second shortest mean survival time, ranking behind liquidation candidates. This signals regulators' willingness to quickly reveal the poor financial conditions of insurers heading towards a conservation state and their tendency to promptly place severely distressed insurers into liquidation.

\section{Independent variables}

The endogenous and exogenous factors associated with insolvency were identified from previous studies on insurance insolvency and financial distress. Focus was given to firm-specific characteristics associated with or activities that constitute excessive risk-taking behaviours. The list of variables employed in this study, after checking for multi-collinearity, is presented in Table 4 . The models include 40 variables, of which 21 are firm-specific qualitative dummies, 14 are firm-specific time-varying and 5 are macroeconomic time-varying. The values of time-varying endogenous and exogenous variables used in the estimation process were updated to the most recent value as an insolvency event occurred. The dynamic estimation process therefore captures changes in the financial characteristics of insurers and macroeconomic conditions over time.

\section{Time-varying variables}

Macroeconomic variables Insolvency peaks are often triggered or exacerbated by a perilous operating climate. ${ }^{49}$ It is thus necessary to account for the macroeconomic conditions prevailing prior to each insolvency event. Moody's Aaa corporate bond yield and S\&P500 return were used to account for the performance of the credit and stockmarkets respectively. Yield curve slope, measured as the spread between 3-month and 10-year Treasury Constant Maturity rates, was included to control for credit conditions and to capture the future prospects of the economy. CPI Inflation rate and Unemployment rate were added to capture the general macroeconomic conditions.

As the insolvency rate tends to correlate with the lagged effects of macroeconomic values (pp. 11-12), ${ }^{50}$ the study applies the approach of Figlewski et al. ${ }^{51}$ to construct each macroeconomic variable as an exponentially weighted average of its lagged observations. Macro variables were updated quarterly during the survival durations of insurers in the study.

Firm-specific variables The financial condition of firms changes over time and tends to deteriorate prior to insolvency. It is thus necessary to control for the variations in firm-specific characteristics. Fourteen variables were employed to capture various aspects such as firm size (Logarithm of average capital and surplus), growth patterns (Capital and surplus growth, Admitted asset growth), cash flows (Logarithm of cash from operation), financial leverage (Liabilities/Liquid assets), reserves (Reserves/

\footnotetext{
${ }^{49}$ Browne and Hoyt (1995); Leadbetter and Dibra (2008); A.M. Best (2009, 2010).

${ }^{50}$ A.M. Best (2009).

${ }^{51}$ Figlewski et al. (2012).
} 
Size and growth (time-varying)

Admitted assets growth (\%)

Capital and surplus growth (\%)

Equity (capital and surplus) (\$000)

Cash flow, liquidity, reserves (time-varying Liabilities/Liquid assets (\%)

Cash from operations $(\$ 000)$

Reserves/Equity (\%)

Underwriting performance (time-varying)

Combined ratio $(\%)$

Operating ratio $(\%)$

Retention ratio (\%)

Net premiums written/Average capital and

surplus $(\%)$

Net premiums written growth $(\%)$
Brockett et al. (2006)

Lee and Urrutia (1996), Chen and Wong (2004), Carson and Hoyt (2003), Brockett et al. (2006)

BarNiv and McDonald (1992), Carson and Hoyt (1995), Browne et al. (2001), Carson and Hoyt (2003), Grace and Klein (2008), A.M. Best (2009, 2010, 2011)

Ambrose and Seward (1988), Brockett et al. (1994),

Carson and Hoyt (2003), Chen and Wong (2004)

Brockett et al. (2006)

Kim et al. (1995), Carson and Hoyt (1995), Browne et al. (2001), Carson and Hoyt (2003), Brockett et al. (2006), A.M. Best $(2009,2010,2011)$

Trieschmann and Pinches (1973), Grace and Hotchkiss (1995), Kim et al. (1995), Sharpe and Stadnik (2007),

A.M. Best (2009)

Kim et al. (1995)

Ambrose and Seward (1988), Harrington and Nelson (1986), Carson and Hoyt (1995), Lee and Urrutia (1996), Barniv et al. (1999), Browne et al. (2001), Carson and Hoyt (2003), Brockett et al. (2006)

Ambrose and Seward (1988), Kim et al. (1995), Lee and Urrutia (1996), Pottier and Sommer (1999), Chen and Wong (2004), Brockett et al. (2006), Sharpe and Stadnik (2007)
Growth in admitted assets

Growth in capital and surplus

Logarithm of average capital and surplus

Total liabilities as a per cent of net admitted cash, equivalent assets and short-term investments

Logarithm of cash flow from operation (CFO), estimated as $\mathrm{Log}$ of $\mathrm{CFO}$ if $\mathrm{CFO}>0$ or $-\mathrm{Log}$ of $(1-\mathrm{CFO})$ if $\mathrm{CFO}<0$ (Loffler and Posch, 2007, p. 19)

Loss and loss adjustment expense reserves as a per cent of equity

Sum of loss ratio, loss adjustment expense ratio, underwriting expense ratio, policyholder dividend ratio. It measures the company's overall underwriting profitability

The combined ratio less the investment income ratio. It measures overall operational profitability from underwriting and investment activities

Net premiums written as a per cent of gross premiums written

Net premium written as a per cent of capital and surplus

Growth in net premium written 
Investment performance (time-varying)

Return on average equity $(\%)$

Net yield on invested assets (\%)

Investment income growth $(\%)$

Organisation form

Dummy stock firm

Dummy mutual firm

Domicile

Dummy West

Dummy Southeast

Dummy Northeast

Dummy Mid-West

Dummy Mid-Atlantic

Business focus

Dummy accident \& health lines focus

Dummy auto focus

Dummy commercial financial lines focus

Dummy commercial general liability focus

Dummy commercial lines focus

Dummy commercial medical malpractice focus

Dummy commercial property focus

Dummy commercial workers compensation focus

Dummy reinsurance focus
BarNiv and McDonald (1992), Lee and Urrutia (1996)

Ambrose and Seward (1988), Brockett et al. (1994), Kim et al. (1995), Chen and Wong (2004)

Ambrose and Seward (1988), Carson and Hoyt (1995), Carson and Hoyt (2003), A.M. Best $(2009,2010)$

Ambrose and Seward (1988), Harrington and Nelson (1986) Cummins et al. (1995), Lee and Urrutia (1996), A.M. Best $(2009,2010)$

Grace et al. (2003), Grace and Klein (2008), A.M. Best (2009, 2010, 2011)

The domicile region of an insurer is based on its registered business address. To capture any geographical effects, five domicile dummies were created, with the Southwest region left uncoded. The dummy takes a value of one if the insurer resides in a geographical region and zero otherwise.

\section{Grace and Klein (2008), A.M. Best (2009, 2010, 2011)}

The business focus designated by SNL is based on the line of business outlined on the Underwriting and Investment Exhibit Part 1 for property-casualty insurers. The lines of business were merged into categories for each filing type. The final focus designation is based on the percentage of net premium written to total net premium written the insurer writes in each of those categories.

To capture any business focus effects, 11 dummies representing 11 business focus lines were created. Firms with Unidentified focus were left uncoded. The dummy takes a value of one if an insurer orients in a business line, and zero otherwise.
Annualised income after taxes as a per cent of average capital and surplus

alised investment return based on average invested assets

The stock (mutual) dummy takes a value of one if the insure is categorised as a stock (mutual) firm by NAIC ownership as Risk retention group, Lloyd organisation, and Reciprocal exchange were left uncoded. 
Dummy P\&C minimum net premium written

Dummy personal lines focus

Maturity

Dummy age ( (less than 10.58 years)

Dummy age2 (between 10.58 and 21.41 years)

Dummy age3 (between 21.41 and 58.25 years)

Macroeconomic (time-varying)

Yield curve slope $(\%)$

CPI inflation rate $(\%)$

Unemployment rate $(\%)$

S\&P500 return $(\%)$

AAA corporate bond yield (\%)

Kim et al. (1995), Carson and Hoyt (2003), A.M. Best (2009,

2010, 2011)

The age since establishment is the length of time from the date on which a firm's general ledger was first opened/the date on which it first conducted business operations to its entry to the study. Three dummies were created representing the $1^{\text {st }}, 2^{\text {nd }}, 3^{\text {rd }}$ quartiles of age distribution, with the $4^{\text {th }}$ quartile left uncoded

Browne et al. (1999), Browne et al. (2001), Partington et al. (2001), Rösch and Sheule (2005), Bonfin (2009)

Grace and Hotchkiss (1995), Liu (2004), Halling and Hayden (2006), A.M. Best $(2009,2010)$

Browne et al. (1999), Browne et al. (2001),

Figlewski et al. (2012)

Browne et al. (1999), Browne et al. (2001), Rösch and Scheule (2005), Figlewski et al. (2012), Bonfin (2009), A.M. Best (2009, 2010), Bellotti and Crook (2009)

Browne and Hoyt (1995), Browne et al. (1999), Browne et al. (2001)
The spread between three-month and 10-year Treasury Constant Maturity Rates, published by U.S. Federal Reserve

Consumer Price Index For All Urban Consumers, published by Bureau of Labor Statistics U.S. Department of Labor

Civilian Unemployment Rate, published by Bureau of Labor Statistics U.S. Department of Labor

The annualised Standard \& Poor's 500 Index return for a quarter derived from daily returns available in WRDS

Moody's Seasoned Aaa Corporate Bond Yield, published by Board of Governors, Federal Reserve System

This table shows the endogenous and exogenous variables employed in this study. Candidate variables were screened from previous studies on insurance insolvency and corporate failure. Variables that exhibited strong multi-collinearity were eliminated. The models include 40 variables, of which 21 dummy variables capture qualitative characteristics, 14 time-varying variables capture financial characteristics of insurers, and five time-varying variables capture macroeconomic conditions. 
Equity), underwriting performance (Retention ratio, Operating ratio, Combined ratio, Net premium written growth, Net premium written/Average capital and surplus), and investment performance (Return on average equity, Net yield on invested assets, Investment income growth).

These variables were measured annually during the survival durations of insurers in the study. ${ }^{52}$ To eliminate outliers, the study applies the approach of Cummins et al. ${ }^{53}$ and Shumway, ${ }^{5}$ in which the annual values of a variable are truncated at the $1^{\text {st }}$ and the $99^{\text {th }}$ percentiles of the annual distribution. The t-test and the Wilcoxon test (not reported) indicate that the descriptive statistics of the financial characteristics of firms experiencing different insolvency outcomes are statistically different. This suggests that different insolvency events are characterised by different endogenous factors and have different underlying determinants.

\section{Time-independent variables}

Twenty-one time-independent variables were created to control for insurers' qualitative characteristics such as organisational form, maturity, primary business line and domicile.

Previous studies found that a stock insurer is more likely to be insolvent and a mutual insurer less so. ${ }^{54}$ Stock companies employ an aggressive underwriting leverage policy, are more active in commercial lines and casualty lines, and have volatile underwriting exposures. In contrast, mutual companies adopt a conservative operating philosophy and concentrate more on personal and property lines. ${ }^{50}$ Compared with the owners of a mutual distressed insurer, the managers of a stock distressed insurer have a higher incentive to take advantage of greater risk levels, as their claim on the assets of the firm is one-sided. ${ }^{55}$ In this study, two dummies were created to account for any ownership effects arising from being a stock or a mutual insurer.

Insurers of different ages exhibit different insolvency vulnerability. Young insurers tend to adopt competitive pricing and aggressive underwriting strategies. They tend to be thinly capitalised and consequently unable to absorb underwriting losses typical of aggressive companies (pp. 2-3). ${ }^{56}$ Immature insurers are therefore more likely to be insolvent than well-established insurers. ${ }^{57}$ This study created three age dummies to represent the first, the second and the third quartile of firm age distribution. These dummies capture any non-linear relationships between firm ages and financial distress. $^{47}$

\footnotetext{
52 Annual (quarterly) financial data of PC insurers are available in SNL Financial as of December 1997 (March 2001). In the interest of creating a sufficient large pool of insurers population with a rich history of insolvency event types that cover different phases of the underwriting cycle and the business cycle in the U.S., the study employs annual firm-specific financial data as of December 1997.

${ }^{53}$ Cummins et al. (1995).

${ }^{54}$ See, for example, Harrington and Nelson (1986), Ambrose and Seward (1988), Cummins et al. (1995), Carson and Hoyt (1995), Lee and Urrutia (1996), Carson and Hoyt (2003), A.M. Best (2009, 2010).

${ }^{55}$ Lee et al. (1997).

56 A.M. Best (2011).

${ }^{57}$ Kim et al. (1995); A.M. Best (2010, 2011).
} 
An insurer's spread of risk is commonly proxied by its underwriting exposures in long-tail vs short-tail business lines. ${ }^{58}$ However, different short-tail/long-tail business lines exhibit statistically different insolvency frequencies during the study period (not reported). This is not surprising as different lines of business are subject to different regulations and exposes insurers to different underwriting risks. ${ }^{59}$ Failure to account for an insurer's primary business line may lead to an underestimation of its revenue volatility and loss exposure, deficient loss reserves ${ }^{60}$ and a suboptimal capital allocation. To control for variation in line-of-business exposure, this study created 11 dummy variables representing 11 primary business lines of PC insurers in the study. These dummy variables allowed the isolation of business line-specific factors which cannot be measured directly, and provided a richer measure than the short-tail and long-tail business lines applied in previous insurance insolvency studies.

This study also employed domicile variables to control for residual effects of factors in a given region. Ideally, I would have constructed a state indicator for each insurer as in Grace et al. ${ }^{1}$ However, the dynamic hazard models already include 40 variables. Employing an additional 50 dummy variables representing 50 states would have reduced the degree of freedom and hindered the compact presentation of the regression results. To keep the number of variables manageable, the study created five domicile dummies representing five geographic regions in the U.S. in which each insurer is domiciled. The dummy takes a value of one if the registered business address of the insurer falls in that region, and zero otherwise.

\section{Methods}

The rejection of the hazard proportionality hypothesis in the section "Competing risks" motivates the use of the Cox's dynamic hazard model (with time-varying covariates), which does not require the proportionality assumption. Following the convention in the insurance literature, this study develops a generic dynamic Cox's hazard model to explore the determinants of generic insolvency events. In addition, this study develops four type-specific dynamic Cox's hazard models to identify the risk factors underlying the four observed insolvency outcomes namely supervision, conservation/others, rehabilitation and liquidation.

The type-specific dynamic Cox's hazard models for insurer $m$ can be expressed as:

$$
h_{s, m}(t, Z, Z(t))=h_{s(0)}(t) \exp \left[Z_{j}^{m} \beta_{j}+Z_{p}^{m}(t) \beta_{p}\right]
$$

where $h_{s, m}(t, Z, Z(t))$ is the insolvency hazard of an event type $s$ at time $t$ given insurer $m$ 's time-independent covariate vector $Z_{j}^{m}$ and insurer $m$ 's time-varying covariate vector $Z_{p}^{m}(t) . h_{s(0)}(t)$ is the baseline hazard of an event type $s$ at time $t$, which is the

\footnotetext{
${ }^{58}$ For example, Harrington and Nelson (1986); Lee and Urrutia (1996).

${ }^{59}$ Cummins et al. (1999).

${ }^{60}$ Deficient loss reserves has been cited as one of the principal causes of insolvency in most of the $2000 \mathrm{~s}$ (Leadbetter and Dibra, 2008; A.M. Best, 2009, p. 20).
} 
hazard with the covariate vector set to zero. $\beta_{p}$ is the vector of estimated coefficients for time-varying covariate vector $Z_{p}^{m}(t) . \beta_{j}$ is the vector of estimated coefficients for time-independent covariate vector $Z_{j}^{m}$.

Firm observations are arranged in event time (gap time) risk sets, which are composed of all the firms that are at risk of an event at time $t$. In this setting, the clock starts when an insurer entered the study and the focus is on the survival duration between the time an insurer entered the study and the time it experienced the first regulatory action. The event time risk set arrangement captures firm-specific macroeconomic influences at every event time and accommodates changes in the economic environment over time.

In forming the risk sets for a type-specific hazard model, the insolvency events of that type (outcome) will be treated as events, and the insolvency events of other types and survived cases will be treated as censored. In forming the risk sets for the generic model, all insolvency outcomes will be treated as equivalent events and survived insurers will be treated as censored. Each insurer contributes only one observation, either an event or a censored observation, to the data set.

The Appendix details the estimation of the time-fixed and time-varying covariates, the estimation of the baseline hazard function, the generation of time-varying probability survival forecasts for holdout insurers, and the Brier score used to evaluate the predictive power of the survival estimates generated by the models.

\section{Estimation and forecast performance results}

\section{Estimation results}

The estimation results are given in Table 5, Panel A. Table 5, Panel B summarises the number of events and censored observations in the estimation and holdout samples. Table 5, Panel C provides the statistics on the goodness of fit of the estimated models.

In the interest of estimating a parsimonious model, the backward stepwise estimation procedure is employed. Variables were retained in the models according to the log-likelihood ratio test, at the 10 per cent level or better, derived from the maximum likelihood procedure used to estimate the models. Most of the selected variables were significant at the 10 per cent level or better based on the Wald $\chi^{2}$ tests. The following discussion focuses on the significant variables present in the generic and type-specific models.

\section{Generic dynamic hazard model}

As shown in Table 5, Panel A (columns 2-4), the hazard of a generic insolvency event depends significantly upon a number of endogenous and exogenous factors. Insurers employing aggressive financial and underwriting leverage strategies (Liabilities/ Liquid assets, Net premium written/Average capital and surplus) are more likely to succumb to insolvency, as are insurers with depleted cash flows from operations (Logarithm of cash from operation), poor Return on average capital \& surplus, low Admitted asset growth and Investment income growth. Insurers less dependent on reinsurance who therefore have less exposure to counterparty credit risk (Retention ration) exhibit a 
Table 5 Cox's dynamic hazard models for generic insolvency events and insolvency events of different types (outcomes)

\begin{tabular}{|c|c|c|c|c|c|c|c|c|c|c|c|c|c|c|c|}
\hline \multirow[t]{3}{*}{ Variables } & \multirow{2}{*}{\multicolumn{3}{|c|}{$\begin{array}{l}\text { Generic dynamic hazard model } \\
\text { All insolvency types combined }\end{array}$}} & \multicolumn{12}{|c|}{ Type-specific dynamic hazard models } \\
\hline & & & & \multicolumn{3}{|c|}{ Model-supervision event } & \multicolumn{3}{|c|}{ Model-conservation/other event } & \multicolumn{3}{|c|}{ Model-rehabilitation event } & \multicolumn{3}{|c|}{ Model-liquidation event } \\
\hline & $\begin{array}{l}\text { Parameter } \\
\text { estimate }\end{array}$ & $\begin{array}{l}\text { Standard } \\
\text { error }\end{array}$ & $\begin{array}{c}\text { Hazard } \\
\text { ratio }\end{array}$ & $\begin{array}{l}\text { Parameter } \\
\text { estimate }\end{array}$ & $\begin{array}{l}\text { Standard } \\
\text { error }\end{array}$ & $\begin{array}{l}\text { Hazard } \\
\text { ratio }\end{array}$ & $\begin{array}{l}\text { Parameter } \\
\text { estimate }\end{array}$ & $\begin{array}{l}\text { Standard } \\
\text { error }\end{array}$ & $\begin{array}{l}\text { Hazard } \\
\text { ratio }\end{array}$ & $\begin{array}{l}\text { Parameter } \\
\text { estimate }\end{array}$ & $\begin{array}{l}\text { Standard } \\
\text { error }\end{array}$ & $\begin{array}{l}\text { Hazard } \\
\text { ratio }\end{array}$ & $\begin{array}{l}\text { Parameter } \\
\text { estimate }\end{array}$ & $\begin{array}{l}\text { Standard } \\
\text { error }\end{array}$ & $\begin{array}{l}\text { Hazard } \\
\text { ratio }\end{array}$ \\
\hline \multicolumn{16}{|l|}{ Panel A: Parameter estimates } \\
\hline \multicolumn{16}{|l|}{ Size and growth (time-varying) } \\
\hline Logarithm of Average capital \& surplus & & & & & & & & & & & & & $-0.69095^{* * *}$ & 0.1681 & 0.501 \\
\hline Capital \& surplus growth (\%) & -0.00918 & 0.00551 & 0.991 & $-0.01452 * *$ & 0.00668 & 0.986 & $0.01475^{* *}$ & 0.00717 & 1.015 & -0.01831 & 0.01117 & 0.982 & & & \\
\hline Admitted assets growth (\%) & $-0.00603 *$ & 0.00443 & 0.994 & & & & $-0.02065^{* *}$ & 0.0094 & 0.98 & $-0.02204 * * *$ & 0.0063 & 0.978 & $-0.0171^{* *}$ & 0.0071 & 0.983 \\
\hline \multicolumn{16}{|l|}{ Cash flow, liquidity, reserves (time-varying) } \\
\hline Logarithm of cash from operations & $-0.0504 * * *$ & 0.01508 & 0.951 & $-0.0646 * * *$ & 0.02412 & 0.937 & & & & & & & & & \\
\hline Liabilities/Liquid assets (\%) & $0.00912 * * *$ & 0.00173 & 1.009 & $0.00775 * * *$ & 0.00207 & 1.008 & $0.01553^{* * *}$ & 0.00269 & 1.016 & $0.01339^{* * *}$ & 0.0031 & 1.013 & $0.01216^{* * *}$ & 0.0043 & 1.012 \\
\hline Reserves/Equity (\%) & & & & & & & $0.00219^{*}$ & 0.0013 & 1.002 & & & & & & \\
\hline \multicolumn{16}{|l|}{ Underwriting performance (time-varying) } \\
\hline Net premiums written growth (\%) & & & & $0.00433^{* * *}$ & 0.00118 & 1.004 & $-0.01077^{* *}$ & 0.00503 & 0.989 & $-0.01303^{* *}$ & 0.00547 & 0.987 & $-0.00979 *$ & 0.0056 & 0.99 \\
\hline $\begin{array}{l}\text { Net premiums written/Average capital } \\
\& \text { surplus }(\%)\end{array}$ & $0.00452^{* * *}$ & 0.00094 & 1.005 & 0.00312 & 0.00194 & 1.003 & $0.00457^{* * *}$ & 0.00177 & 1.005 & $0.00638^{* * *}$ & 0.00145 & 1.006 & & & \\
\hline Retention ratio (\%) & $-0.00666^{* *}$ & 0.00331 & 0.993 & $-0.01056^{* *}$ & 0.00534 & 0.989 & $-0.02127^{* * *}$ & 0.00783 & 0.979 & & & & $0.02466^{* *}$ & 0.0097 & 1.025 \\
\hline Operating ratio (\%) & & & & & & & & & & & & & $-0.00822 * * *$ & 0.0017 & 0.992 \\
\hline Combined ratio (\%) & & & & & & & & & & & & & $0.00303 * *$ & 0.0013 & 1.003 \\
\hline \multicolumn{16}{|l|}{ Investment performance (time-varying) } \\
\hline Return on average capital \& surplus (\%) & $-0.02537 * * *$ & 0.00334 & 0.975 & $-0.0242 * * *$ & 0.00579 & 0.976 & $-0.0321 * * *$ & 0.0069 & 0.968 & $-0.02611^{* * *}$ & 0.00652 & 0.974 & $-0.03286 * * *$ & 0.0061 & 0.968 \\
\hline Net yield on invested assets (\%) & & & & & & & & & & & & & $-0.30599 *$ & 0.1711 & 0.736 \\
\hline Investment Income Growth (\%) & $-0.00543^{*}$ & 0.00312 & 0.995 & -0.01122 & 0.00737 & 0.989 & & & & & & & 0.00548 & 0.0043 & 1.005 \\
\hline \multicolumn{16}{|l|}{ Organization form } \\
\hline \multicolumn{16}{|l|}{ Dummy stock firm } \\
\hline \multicolumn{16}{|l|}{ Dummy mutual firm } \\
\hline \multirow{2}{*}{\multicolumn{16}{|c|}{$\begin{array}{l}\text { Maturity } \\
\text { Dummy agel ( } 1^{\text {st }} \text { quartile of age } \\
\text { distribution) }\end{array}$}} \\
\hline & & & & & & & & & & & & & & & \\
\hline $\begin{array}{l}\text { Dummy age } 2\left(2^{\text {nd }} \text { quartile of age }\right. \\
\text { distribution) }\end{array}$ & & & & & & & $0.83401^{*}$ & 0.43342 & 2.303 & & & & & & \\
\hline $\begin{array}{l}\text { Dummy age } 3\left(3^{\text {rd }} \text { quartile of age }\right. \\
\text { distribution) }\end{array}$ & & & & $0.70022 * *$ & 0.33249 & 2.014 & & & & & & & & & \\
\hline
\end{tabular}




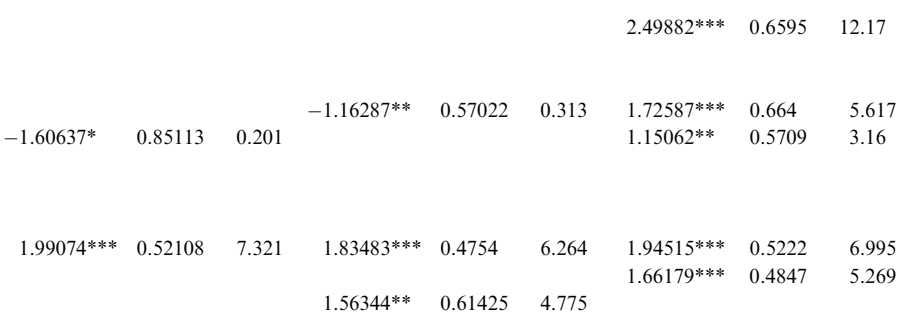

Dummy personal lines focus

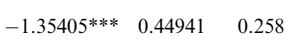

Generic estimation sample (all insolvency combined)

\begin{tabular}{lll}
\hline Supervision est. sample $\quad$ Conservation other est. sample $\quad$ Rehabilitation est. sample $\quad$ Liquidation est. sample
\end{tabular}

Panel B: Summary of the number of event and

censored values

Total observations: 1,362

Event observations: 126

Censored observations: 1,236

Total observations

1,362

$\begin{array}{lll}-1.64182 & 0.54171 & 0.194\end{array}$

$-0.91801 * * \quad 0.40847 \quad 0.399$

$\begin{array}{lll}-1.60605 & 0.56065 & 0.201\end{array}$

$1.02255^{* *} \quad 0.43214 \quad 2.78$

Generic holdout sample (all insolvency combined)

Event (Type-specific insolvency)

Censored observations

1,315

$100 \%$
$3.45 \%$

1,362

26

1,336

$100 \%$
$1.91 \%$

$1.91 \%$
$98.09 \%$

1,362
35

$100 \%$

$2.57 \%$

$1,362 \quad 100 \%$

Type-specific insolvency event holdout samples

\begin{tabular}{|c|c|c|c|c|c|c|c|c|c|}
\hline \multirow[b]{3}{*}{ Total observations: 736} & & \multirow{2}{*}{\multicolumn{2}{|c|}{ Supervision holdout sample }} & \multirow{2}{*}{\multicolumn{2}{|c|}{ Conservation/Other holdout sample }} & \multirow{2}{*}{\multicolumn{2}{|c|}{ Rehabilitation holdout sample }} & \multirow{2}{*}{\multicolumn{2}{|c|}{ Liquidation holdout sample }} \\
\hline & \multirow[b]{2}{*}{ Total observations } & & & & & & & & \\
\hline & & 736 & $100 \%$ & 736 & $100 \%$ & 736 & $100 \%$ & 736 & $100 \%$ \\
\hline
\end{tabular}


Supervision holdout sample Conservation/Other holdout sample Rehabilitation holdout sample Liquidation holdout sample

\begin{tabular}{|c|c|c|c|c|c|c|c|c|c|}
\hline Event observations: 69 & Event (Type-specific insolvency) & 30 & $4.08 \%$ & 11 & $1.49 \%$ & 17 & $2.31 \%$ & 11 & $1.49 \%$ \\
\hline Censored observations: 667 & Censored observations & 706 & $95.92 \%$ & 725 & $98.51 \%$ & 719 & $97.69 \%$ & 725 & $98.51 \%$ \\
\hline
\end{tabular}

Censored observations: 667

Censored observations

Type-specific dynamic hazard model

Generic dynamic $\quad$ Model-supervision event Model-conservation/Other event $\quad$ Model-rehabilitation event $\quad$ Model-liquidation event

hazard model

Model-supervision event

Model-conservation/Other event

Model-rehabilitation event

Model-liquidation event

\section{Panel C: Model goodness of fit}

-2 Log Likelihood (without covariates)

-2 Log Likelihood (with covariates)

$1,760.3$

Likelihood ratio $\chi^{2}$

$\begin{array}{cc}1,760.38 & 657.967 \\ 1,251.294 & 466.804 \\ 509.08 & 191.1631 \\ 18 & 13 \\ <0.0001 & <0.0001\end{array}$

358.944
224.684
134.260
14

491.356
288.748

288.748

202.608

Degrees of freedom

$<0.0001$

$<0.000$

13

Panel A shows the parameter, standard error and hazard ratio of the significant variables in the generic and type-specific dynamic Cox's hazard models estimated as in Eq. (2). The generic dynamic hazard model treats all insolvency outcomes as equivalent events. Each type-specific dynamic hazard model treats the insolvency type (outcome) being modelled as an event, and treats other insolvency types and survived insurers as censored. The values of time-varying firm-specific (macroeconomic) variables used in the estimation process were updated to the most recent annual (quarterly) value as an insolvency event occurred. Parameter estimates are given first followed by the corresponding $p$-value based on Wald $\chi^{2}$ tests. ${ }^{* * *} p$-value $\leqslant 1$ per cent, $* * 1$ per cent $<p$-value $\leqslant 5$ per cent, $* 5$ per cent $<p$-value $\leqslant 10$ per cent. In interpreting Panel A, a negative coefficient reduces the hazard and therefore reduces the probability of the insolvency event being modelled. The reported hazard ratios represent the relative change in the hazard for a one unit change in the independent variable.

Panel B shows the number of insurers, the number of event and censored observations for each financial distress outcome and for all outcomes combined in the estimation and holdout samples. Panel C shows the model fit statistics. The term Log-Likelihood is the logarithm of the maximum likelihood estimator for the estimated model. The likelihood ratio is calculated as $L R=2\left(L_{1}-L_{0}\right)$ where $L_{1}$ is the log-likelihood of the estimated model (with covariates) and $L_{0}$ is the log-likelihood of the model without covariates. As shown in Panel C, the explanatory power of each model is significantly improved as variables are added. The likelihood ratio statistics report that this improvement is significant at better than the 1 per cent level. 
greater tendency to survive. It is notable that firm size (Logarithm of average capital \& surplus) and underwriting performance measures (Combined ratio, Operating ratio) are not significant in determining the probability of a generic event.

Among firm-specific variables, the primary business line is the key determinant of insurance failure. Insurers specialising in Auto and Commercial worker compensation lines are 86 and 68.4 per cent respectively more likely to be insolvent. In contrast, being in Commercial line, Commercial property line, Personal line or having annual net premiums written of less than US\$1 million ( $P \& C$ minimum net premium written) reduces the failure risk by $65.7,78,84.1$ and 65.3 per cent, respectively. Other qualitative characteristics such as organisational form, maturity and domicile region are not significant.

Macroeconomic factors have substantial effects on the hazard of a generic insolvency event. A 1 per cent increase in Unemployment rate makes an insurer 198 per cent more likely to experience a regulatory intervention. Increasing the Yield curve slope, Moody's Aaa corporate bond yield and S\&P500 return by 1 per cent reduces the insolvency probability by $74.2,59.1$ and 2.7 per cent, respectively. The large coefficients of Yield curve slope and Moody's Aaa corporate bond yield reflect the fact that PC insurers adopt a conservative investment philosophy and primarily invest in investment-grade rated debt instruments. ${ }^{61}$

A valid question is what happens when distinctions are made among different types of insolvency events? Specifically, are the effects of covariates the same or different across event types?

\section{Type-specific hazard models}

As shown in Table 5, Panel A (columns 5-16), the four type-specific models share some common features with the generic model discussed above. Insurers characterised by poor Return on average capital \& surplus and aggressive financial leverage exposure (Liabilities/Liquid assets) are vulnerable to any insolvency event. Those with excessive insurance leverage exposure (Net premium written/Average capital \& surplus) are more likely to experience a non-liquidation intervention. Insurers with a rapid growth in admitted assets (Admitted asset growth) present a lower receivership risk. Business lines have a substantial impact whereas organisational forms are not significant in any model. While the foregoing provides a general picture of the results, there are marked differences across the models.

The type-specific models feature some common significant variables (Capital \& surplus growth, Net premium written growth and Retention ratio). However, their coefficient signs reverse across models. Insurers with a rapid growth in net premiums written (Net premium written growth), commonly associated with aggressive expansion strategies in new lines of business, are more likely to be supervised but less likely to be in receivership. Insurers with a rapid growth in capital and surplus (Capital \& surplus growth) are more vulnerable to a conservation order but less susceptible to a supervision event.

${ }^{61}$ Grace and Klein (2008). 
66

The Retention ratio indicates the risks an insurer retains rather than ceding to reinsurers. Insurers who actively transfer risks and are highly interconnected to reinsurers have an unfavourable record regarding supervision and conservation events. This can be attributed to the greater counterparty credit risk they assume through reinsurance transactions. On the other hand, these insurers have a lower liquidation probability. This is consistent with the "too interconnected to fail" phenomenon. It may be necessary to prevent a highly interconnected insurer from being liquidated if its failure may have a ripple effect throughout the financial system.

Insolvencies of different outcomes are characterised by different underlying factors. Firms with thin cash flows from operations (Logarithm of cash from operations) are potential targets for administrative supervision. Those setting aside more reserves in relation to their equity (Reserves/Equity) are more likely to receive a conservation order. Insurers of small sizes (Logarithm of average capital \& surplus) or who record a poor underwriting and investment performance (Combined ratio, Net yield on invested assets) are at a greater liquidation risk.

Business line indicators are found to be significant in every model. In most cases, dummies present in the generic model are also significant (with similar coefficient signs) in the type-specific model(s). The business line coefficients are generally much larger in the models for receivership events than in the model for a generic event. For example, being in Commercial worker compensation focus increases the risk of a supervision and a conservation/other event by 148.5 and 685.2 per cent respectively, whereas it only makes a generic event 68.4 per cent more likely. Insurers focused in Auto are particularly susceptible to receivership proceedings. Being in this line, while raising the probability of a generic event by 86 per cent, substantially increases the hazard of a conservation/other, a rehabilitation and a liquidation event by 632,526 , and 599 per cent respectively. The primary causes of insolvencies in these two lines are inadequate pricing, deficient loss reserves and rapid growth. Auto insurers' vulnerability can also be attributed to their small size (p. 19). ${ }^{50}$

Several business line dummies, which are not significant in the generic model, have particularly strong effects in the models for receivership proceedings. Being in Commercial medical malpractice focus and Reinsurance focus makes an insurer 501.8 and 564.9 per cent respectively more vulnerable to a conservation/other event. Focusing in the Commercial financial line (Commercial general liability line) raises the liquidation (rehabilitation) hazard by 426.9 per cent (377.5 per cent). The primary factors associated with insolvencies in Commercial lines are poor underwriting performance and inadequate pricing (pp. 31-32) ${ }^{27}$ whereas dramatic catastrophe losses from severe and frequent weather-related events constitute one of the main reasons for insolvencies in Reinsurance.

The models for outcome-specific events markedly differ from the model for a generic event as evidenced by the strong impact of maturity and domicile factors. Insurers categorised in the second and the third age quartile (Dummy age2, Dummy age3), respectively, are 130.3 and 101.4 per cent more likely to receive a conservation and a supervision order. Immature firms in the first age quartile are not susceptible to any insolvency event, a finding which is in direct contrast to previous insurance studies.

The impact of domicile factors varies substantially across models. Residing in the West region raises the liquidation hazard by over 11 times. Being incorporated in the 
mid-West area makes an insurer 68.7 per cent less likely to be rehabilitated but 461.7 per cent more likely to be liquidated. Registering in the mid-Atlantic area reduces the probability of a conservation/other event by 80 per cent but increases the hazard of a liquidation event by 216 per cent. Several factors contribute to a particularly high liquidation risk in the West, mid-West and mid-Atlantic regions. Insurers in these areas are highly vulnerable to natural disasters. California and Alaska make up part of the Pacific Ring of Fire, an area of heavy volcanic activity and earthquakes. Although most insurers cede catastrophe losses to reinsurers, "even the most appropriate reinsurance policies offer limited protection" (p. 34). ${ }^{27}$ Volatility in property lines related to above-normal frequency and severity of natural disasters and greater building density in areas prone to weather-related events place additional pressure on regional insurers and single-state writers concentrated in the affected states. In addition, states such as California have been "more transparent in reporting impairments", which inflated its insolvency incidences relative to other states. California also observed "a rise in impairments after the state's workers' comp market was granted wider flexibility in rates in 1995" (p. 32). ${ }^{27}$ Furthermore, insurers concentrated in New York were hit hard by the World Trade Center-related insured losses following the devastating terrorist attack in September 2001. It is likely that, triggered by unusual escalation in loss patterns/loss exposures, distressed insurers in the West, mid-West and mid-Atlantic areas experience deteriorating financial conditions so dramatically and so rapidly that any attempt to prolong their life would be detrimental to their policyholders and creditors. The optimal regulatory action is therefore to immediately place them into liquidation.

A striking feature of the type-specific models is that macroeconomic factors are not significant in determining the hazards of insolvency events other than rehabilitation. This can be attributed to several factors. First, fluctuations in economic activities impact on insurers' underwriting and investment performance. Insurers generally review and adjust their leverage, liquidity and reserves policies along the business cycle. Changes in insurers' financial characteristics capture the evolution of the macroeconomic environment over time, and these changes are accounted for in the estimated dynamic hazard models with time-varying covariates. Second, insurers at different stages of financial deterioration exhibit different vulnerabilities to exogenous risk factors. Rehabilitation candidates are particularly susceptible to unfavourable macroeconomic developments given regulators' leniency towards these insurers, allowing their poor financial conditions and problems to linger for some time. Third, an insurer is placed into rehabilitation if its state regulator believes that there is a possibility of restoring the company to the marketplace as a viable entity. ${ }^{62}$ However, a regulator's evaluation regarding the distressed insurer's viability is largely influenced by the prevailing macroeconomic conditions. Similarly, a regulator's decision regarding the time a troubled insurer is placed into rehabilitation and the optimal rehabilitation plan needed to revitalise it are functions of the macroeconomic environment. Adverse conditions, for example an elevated Unemployment rate, an inverted Yield curve slope, a declining Moody's Aaa corporate bond yield and CPI

${ }^{62}$ Bickford (2004); Mayer et al. (2011). 
inflation rate, can push an already vulnerable insurer over the survival edge and trigger the occurrence of a rehabilitation event.

Overall, the significant factors underlying different insolvency outcomes vary. It is pertinent to ask whether these differences are the result of random variations.

\section{Test of equal coefficients across event types}

A test of the null hypothesis that $\beta_{s}=\beta$, where $\beta_{s}$ is the vector of coefficients for event type $s$, answers the above question (p. 198). ${ }^{43}$ The test statistic can be constructed from the term ( -2 Log-likelihood), which measures the significant improvement in the explanatory power of each estimated model as variables are added (Table 5, Panel C). Summing the values of the terms ( -2 Log-likelihood) for four type-specific hazard models yields a total of 1,161.64. Subtracting this from the corresponding value of 1,251.29 for the generic hazard model yields a difference of 89.65. This is the likelihood-ratio $\chi^{2}$ statistic for the null hypothesis, which has 38 degrees of freedom (the difference in the number of estimated parameters) for a $p$-value less than 1 per cent. The null hypothesis that the coefficients are equal across event types can therefore be rejected. This suggests that different models are required for different insolvency outcomes.

The next question is whether the type-specific hazard models exhibit better predictive accuracy in forming time-varying survival forecasts than the generic hazard model?

\section{Predictive performance assessment}

Figure 2 depicts the time-varying survival forecasts formed by the generic dynamic hazard model for five holdout insurers, one survived and four insolvent in four different manners. The five holdout insurers were chosen randomly, except that each experienced a different outcome, from the holdout sample including 736 insurers (69 events and 667 survived observations). For ease of assessment, the actual survival status/insolvency outcome of each holdout insurer is recorded and mapped against the survival probability estimates.

The time structures of survival probability estimates, as shown in Figure 2, illustrate the usefulness of the dynamic hazard model (for generic events) in providing regulators with an early warning of financial distress. However, the generic model fails to provide any insight into the appropriate regulatory action that should be taken against a troubled insurer. The type-specific dynamic hazard models overcome this limitation and offer regulators the possibility of identifying those insurers most susceptible to certain insolvency outcomes. Regulators should run each type-specific dynamic hazard model separately for each holdout insurer. Of the estimates generated by the type-specific models for a given insurer at a specific forecast time, the estimate with the lowest survival probability is most useful in aiding regulators to detect a troubled insurer at an early stage and to choose the appropriate regulatory action that should be commenced.

To evaluate the forecast performance of the type-specific dynamic hazard models in relation to the generic dynamic hazard model, the Brier score is used. A Brier score of zero indicates perfect prediction ability and a Brier score of one indicates the worst 


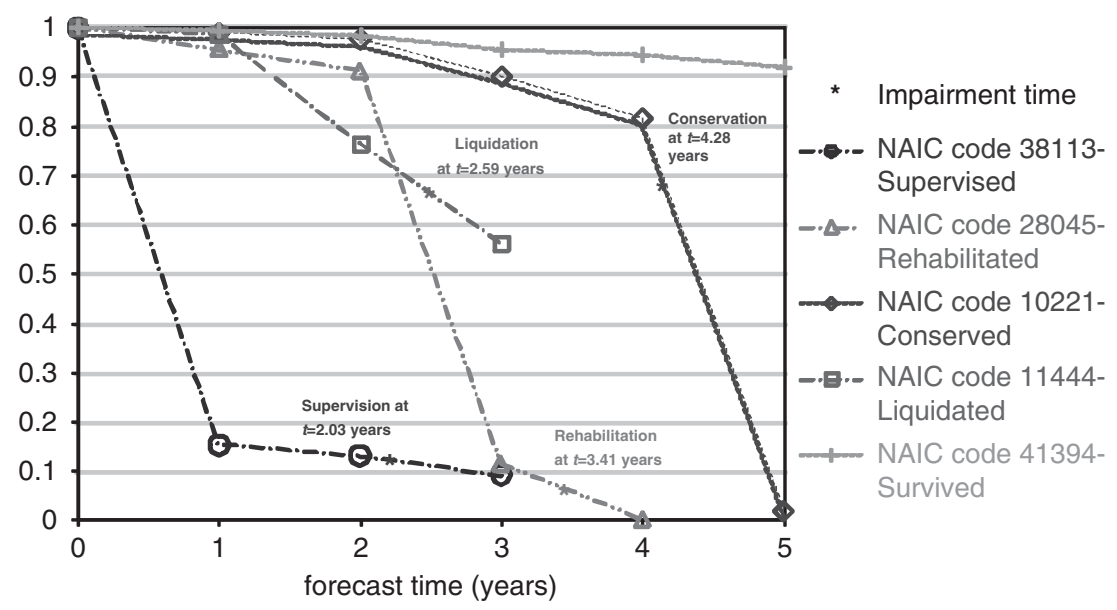

Figure 2. Time-varying probability survival estimates formed by the generic dynamic hazard model for five holdout insurers.

Note: This figure depicts the time-varying survival estimates generated by the generic dynamic hazard models for five holdout insurers, one survived and four failed in four different manners. Each insurer, identified by a unique NAIC code, was chosen randomly from the holdout sample except that each experienced a different outcome. The status of each insurer, the insolvency time and the insolvency outcome of each insolvent insurer were recorded and mapped against the time-varying survival forecasts.

Table 6 Brier score of survival probability estimates generated by the estimated models

\begin{tabular}{|c|c|c|c|c|c|}
\hline Forecast time (years) & 1 & 2 & 3 & 4 & 5 \\
\hline Naive model & $25 \%$ & $25 \%$ & $25 \%$ & $25 \%$ & $25 \%$ \\
\hline Generic dynamic hazard model & $8.99 \%$ & $7.95 \%$ & $6.81 \%$ & $5.4 \%$ & $3.87 \%$ \\
\hline Dynamic hazard model for supervision events & $4.05 \%$ & $3.60 \%$ & $3.52 \%$ & $3.09 \%$ & $2.04 \%$ \\
\hline Dynamic hazard model for conservation/ other events & $1.49 \%$ & $1.51 \%$ & $1.56 \%$ & $1.10 \%$ & $0.73 \%$ \\
\hline Dynamic hazard model for rehabilitation events & $4.29 \%$ & $4.19 \%$ & $4.03 \%$ & $3.68 \%$ & $3.87 \%$ \\
\hline Dynamic hazard model for liquidation events & $1.45 \%$ & $1.27 \%$ & $0.68 \%$ & $0.57 \%$ & $0.46 \%$ \\
\hline
\end{tabular}

This table reports the Brier scores (Brier, 1950) for time-varying survival estimates generated by the generic and the four type-specific dynamic hazard models for all firms in the holdout sample. The Brier score for a given time horizon measures the average square of the errors between probability survival estimates for that time horizon and actual survival status of all holdout insurers available at that time horizon. The Brier score varies between 0 and 100 per cent. A naive model generating random forecasts has a Brier score of 25 per cent. The lower the Brier score, the more accurate the probability survival estimates.

possible predictive accuracy. The Brier score of probability survival estimates generated by the five estimated models for all firms in the holdout sample formed at yearly intervals over the five-year forecast horizon are presented in Table 6.

The Brier scores of the generic model were used as the benchmarks. As shown in Table 6, within a five-year forecast horizon, the type-specific models are more accurate than the generic model in assigning the lowest survival estimates to the riskiest firms. Holdout insurers that subsequently became insolvent were flagged, with a high degree 
of accuracy, as potential candidates for specific insolvency events in years prior to their actual failures. The predictive power of the type-specific models can be attributed to the employment of endogenous and exogenous time-varying variables, which capture the evolution of firm-specific characteristics and macroeconomic conditions that led to a rapid deterioration in the credit quality of insurers susceptible to specific insolvency events.

\section{Conclusion}

This study examines regulatory actions commenced against a large sample of financially distressed PC insurers during the period January 1998-June 2010. The study develops dynamic hazard models to identify the key risk factors that make individual PC insurers most vulnerable to certain types of insolvency outcomes. It is found that the hazards for different insolvency outcomes are unequal and disproportionate. Regulators tend to be prompt in placing severely distressed insurers into liquidation and in revealing poor financial conditions of insurers heading towards conservation events. On the other hand, regulators seem to exhibit greater leniency towards insurers who are candidates for rehabilitation.

The study finds strong evidence that insurance companies heading towards different insolvency routes exhibit different underlying risk factors. Insurers adopting aggressive underwriting leverage strategies tend to have an unfavourable experience towards a non-liquidation intervention, whereas those characterised by poor Admitted asset growth or focused in Auto business line are susceptible to receivership proceedings.

Insurers in the third age quartile with depleted Cash from operations or focused in Commercial workers compensation line are potential targets for administrative supervision. Insurers with substantial reserves (in relation to their equity) and those in the second age quartile have a higher conservation hazard, as are insurers in Commercial medical malpractice, Commercial workers compensation and Reinsurance lines. Insurers of small size, with poor investment returns, focused in Commercial financial line or domiciled in disaster-prone areas such as West, mid-West, mid-Atlantic are at a greater risk of liquidation. Perilous macroeconomic conditions do not affect the occurrence and the timing of insolvencies other than rehabilitation events. Insurers operating under an adverse environment characterised by elevated Unemployment rate, inverted Yield curve slope and declining Moody's Aaa corporate bond yield are vulnerable to the rehabilitation proceedings, as are insurers in the Commercial general liability line.

Regulators tend to favour certain regulatory action(s) in circumstances associated with excessive risk-taking behaviours. For example, insurers with a rapid growth in net premiums written, typically associated with aggressive expansion strategies in new lines of business, are at greater risk of being supervised, but at lower risk of being placed in receivership proceedings. Insurers characterised by an excessive growth in capital and surplus are more vulnerable to a conservation order, but less susceptible to supervision and rehabilitation orders. Insurers exhibiting rapid growth in investment income, commonly associated with excessive risky investment strategies, have a higher 
liquidation probability, but a lower supervision hazard. Insurers substantially exposed to counterparty credit risk via reinsurance are less likely to be liquidated, but more likely to be supervised or conserved.

The differences observed across the hazard models for type-specific events and the model for generic events are not due to random variations, suggesting that insolvency events of different outcomes are distinct phenomena. The validation results show that, within a five-year forecast horizon, the outcome-specific models exhibit better forecast performance than the generic model. The results of this study provide regulators with the means to recognise early warnings of financial distress, aid regulators in prioritising troubled insurers and identifying the areas most likely to reveal material problems, and inform regulators about the preventative/corrective actions that should be taken under specific circumstances.

A natural extension of this study would be to explore the regulatory environment across states, for example, rate regulations system, state regulatory budgets and regulatory competition. ${ }^{63}$ The timing and the extent of regulatory actions are a function of the state regulatory environment, the resources regulators can utilise for solvency oversight, and the capacity of regulators to quickly identify distressed insurers. Future work could also be directed to examine the effects of natural disaster frequency and severity on PC insurer insolvencies.

The results of this study are limited by the data used, which include only the first regulatory action taken against troubled insurers. It has therefore not been possible in this study to examine discretionary delays by regulators in taking the formal actions that are supposed to precede liquidation. An insurer may experience multiple regulatory interventions before being liquidated or merged by a court order. ${ }^{64}$ If financial distress is viewed as an illness process, non-liquidation interventions can be regarded as diagnostic events, whereas liquidation and forced merger can be regarded as death and reincarnation respectively. Using data comprising the complete history of insolvency and forced merger events, it would be relevant to model the duration since the first event time to the liquidation/forced merger time and to examine regulatory forbearance behaviours. Alternatively, the study could be extended by modelling the full time-course of recurrent insolvency events, taking the specific order and the type of regulatory actions into account. Such research would shed light on the effectiveness of preventative/remedial actions and their impact on the risk of a subsequent liquidation/ forced merger event.

\section{Acknowledgements}

This project was conducted during my post-doctoral study at the University of Munich (LMU). Many thanks to Andreas Richter and the Institute for Risk and Insurance Management for hosting me and supporting this project, and to Susanne Weber and the Center for Advanced Studies for the research

\footnotetext{
${ }^{63}$ Single-state insurers are subject to oversight by only one regulator and have a better ability than multistate insurers to lobby the local regulator for leniency regarding solvency-related regulatory interventions (Grace et al., 2003).

${ }^{64}$ Barniv and Hathorn (1997, p. 109) suggested that "regulators and other participants in the insurance industry consider and use acquisitions to avert insolvencies".
} 
fellowship. Thanks are also due to Glenn Boyle for conference funding, to Joseph Callaghan, Bob Kelly, Graham Partington, and the two referees for their helpful comments.

\section{References}

Allison, P.D. (1984) Event History Analysis: Regression for Longitudinal Event Data, Sage university papers, Quantitative Applications in the Social Sciences, No. 07-046, Beverly Hills, CA: Sage Publications.

Allison, P.D. (1995) Survival Analysis Using SAS: A Practical Guide, Cary, NC: SAS Institute Inc.

A.M. Best Company Inc (2009) U.S. Property/Casualty 1969-2008 Impairment Review: Real Estate's Title Insurers Lead 2008 P/C Financial Impairments, Oldwick, NJ: A.M. Best.

A.M. Best Company Inc (2010) U.S. Property/Casualty 1969-2009 Impairment Review: P/C Financial Impairments Rise Markedly Since '07 Low, Oldwick, NJ: A.M. Best.

A.M. Best Company Inc (2011) U.S. Property/Casualty 1969-2010 Impairment Review: Commercial Lines Dominated Financial Impairments in 2010, Oldwick, NJ: A.M. Best.

Ambrose, J.M. and Seward, J.A. (1988) 'Best's ratings, financial ratios and prior probabilities in insolvency prediction', The Journal of Risk and Insurance 55(2): 229-244.

Andersen, P.K. (1992) 'Repeated assessment of risk factors in survival analysis', Statistical Methods in Medical Research 1(3): 297-315.

BarNiv, R. and Hathorn, J. (1997) 'The merger or insolvency alternative in the insurance industry', The Journal of Risk and Insurance 64(1): 89-113.

BarNiv, R., Hathorn, J., Mehrez, A. and Kline, D. (1999) 'Confidence intervals for the probability of insolvency in the insurance industry', The Journal of Risk and Insurance 66(1): 125-137.

BarNiv, R. and McDonald, J. (1992) 'Identifying financial distress in the insurance industry: A synthesis of methodological and empirical issues', The Journal of Risk and Insurance 59(4): 543-573.

Bellotti, T. and Crook, J. (2009) 'Credit scoring with macroeconomic variables using survival analysis', Journal of the Operational Research Society 60(12): 1699-1707.

Bessler, D. and Ruffley, R. (2004) 'Prequential analysis of stock market returns', Applied Economics 36(5): 399-412.

Bhattacharjee, A., Higson, C., Holly, S. and Kattuman, P. (2009) 'Macroeconomic instability and business exit: Determinants of failures and acquisitions of UK firms', Economica 76(301): 108-131.

Bickford, P. (2004) Who protects us from the receiver?, Paper presented at the 2004 American Conference Institute Conference on Insurance Insolvency, New York.

Bonfin, D. (2009) 'Credit risk drivers: Evaluating the contribution of firm level information and of macroeconomic dynamics', Journal of Banking \& Finance 33(2): 281-299.

Brier, G. (1950) 'Verification of forecasts expressed in terms of probability', Monthly Weather Review 78(1): 1-3.

Brockett, P.L., Cooper, W.W., Golden, L.L. and Pitaktong, U. (1994) 'A neural network method for obtaining an early warning of insurer insolvency', The Journal of Risk and Insurance 61(3): 402-424.

Brockett, P.L., Golden, L.L., Jang, J. and Yang, C. (2006) 'A comparison of neural network, statistical methods, and variable choice for life insurers' financial distress prediction', The Journal of Risk and Insurance 73(3): 397-419.

Browne, M., Carson, J. and Hoyt, R. (1999) 'Economic and market predictors of insolvencies in the lifehealth insurance industry', The Journal of Risk and Insurance 66(4): 643-659.

Browne, M., Carson, J. and Hoyt, R. (2001) 'Dynamic financial models of life insurers', North American Actuarial Journal 5(2): 11-26.

Browne, M. and Hoyt, R. (1995) 'Economic and market predictors of insolvencies in the property-liability insurance industry', The Journal of Risk and Insurance 62(2): 309-327.

Carson, J. and Hoyt, R. (1995) 'Life insurer financial distress: Classification models and empirical evidence', The Journal of Risk and Insurance 62(4): 764-775.

Carson, J. and Hoyt, R. (2003) 'An empirical examination of sample selection methods in the context of life insurer financial distress', The Journal of Insurance Issues 26(2): 114-128.

Chancharat, N., Tian, G., Davy, P., McCrae, M. and Lodh, S. (2010) 'Multiple states of financially distressed companies: Tests using a competing-risks model', Australasian Accounting Business and Finance Journal 4(4): 27-44. 
Chen, L., Yen, M., Wu, H., Liao, C., Liou, D., Kuo, H. and Chen, T.H. (2005) 'Predictive survival model with time-dependent prognostic factors: Development of computer-aided SAS macro program', Journal of Evaluation in Clinical Practice 11(2): 181-193.

Chen, R. and Wong, K. (2004) 'The determinants of financial health of Asian insurance companies', The Journal of Risk and Insurance 71(3): 469-499.

Cox, D.R. (1972) 'Regression models and life tables', Journal of the Royal Statistical Society 34(2): 187-220.

Cox, D.R. and Oakes, D. (1984) Analysis of Survival Data, London: Chapman \& Hall.

Cummins, J.D., Harrington, S.E. and Klein, R. (1995) 'Insolvency experience, risk-based capital and prompt corrective action in property-liability insurance', Journal of Banking \& Finance 19(3-4): 511-527.

Cummins, J.D., Tennyson, S. and Weiss, M.A. (1999) 'Consolidation and efficiency in the US life insurance industry', Journal of Banking \& Finance 23(2-4): 325-357.

Dembeck, J. (2008) 'Insurance regulation in a nutshell', from www.pli.edu/emktg/toolbox/Insur_Reg22.doc, accessed 15 August 2012.

Dyrberg, A. (2004) Firms in financial distress: An exploratory analysis, Working Paper No.17, Danmarks Nationalbank and Centre for Applied Microeconometrics (CAM), Institute of Economics, University of Copenhagen, Copenhagen.

Figlewski, S., Frydman, H. and Liang, W. (2012) 'Modeling the effect of macroeconomic factors on corporate default and credit rating transitions', International Review of Economics \& Finance 21(1): 87-105.

Grace, M., Harrington, S. and Klein, R. (1998) 'A risk-based capital and solvency screening in propertyliability insurance: Hypotheses and empirical tests', The Journal of Risk and Insurance 65(2): 213-243.

Grace, M. and Hotchkiss, J. (1995) 'External impacts on the property-liability insurance cycle', The Journal of Risk and Insurance 62(4): 738-754.

Grace, M. and Klein, R. (2008) Understanding property-casualty insurance profits: The importance of financial strength, working paper, from www.aiadc.org/AIAdotNET/docHandler.aspx?DocID =319377, accessed 15 April 2011.

Grace, M., Klein, R. and Phillips, R. (2003) Insurance company failures: Why do they cost so much?, working paper No. 03-1, Center for Risk Management and Insurance Research, Georgia State University.

Grunert, J., Norden, L. and Weber, M. (2005) 'The role of non-financial factors in internal credit ratings', Journal of Banking \& Finance 29(2): 509-531.

Halling, M. and Hayden, E. (2006) Bank failure prediction: A two-step survival time approach, working paper, from www.ssrn.com/abstract $=904255$, accessed 30 March 2010.

Harhoff, D., Stahl, K. and Woywode, M. (1998) 'Legal form, growth and exit of West German firms: Empirical results for manufacturing, construction, trade and service industries', The Journal of Industrial Economics 46(4): 453-488.

Harrington, S.E. and Nelson, J.M. (1986) 'A regression-based methodology for solvency surveillance in the property-liability insurance industry', The Journal of Risk and Insurance 53(4): 583-605.

He, Q., Chong, T., Li, L. and Zhang, J. (2010) 'A competing risks analysis of corporate survival', Financial Management 39(4): 1697-1718.

Hensher, D.A. and Jones, S. (2007) 'Forecasting corporate bankruptcy: Optimizing the performance of the mixed logit model', Abacus 43(3): 241-264.

Hensher, D.A., Jones, S. and Greene, W.H. (2007) 'An error component logit analysis of corporate bankruptcy and insolvency risk in Australia', Economic Record 83(260): 86-103.

Johnson, S., Dynan, B., Armstrong, J., Johnson, W., Blumer, R., Peterson, R., Hartz, D., Johnston, J., Vacca, D., Cornyn, B. and Martin, C. (2005) A Comparison of the Insurance and Banking Regulatory Frameworks for Identifying and Supervising Companies in Weakened Financial Condition, Report of the National Association of Insurance Commissioners (NAIC) and the Federal Reserve System Joint Troubled Company Subgroup, from www.federalreserve.gov/boarddocs/staffreports/naicfrs/naicfrs.pdf.

Johnstone, D. (2002) 'More on the relative efficiency of probability scoring rules', Journal of Statistical Computation and Simulation 72(1): 11-14.

Kim, Y., Anderson, D.R., Amburgey, T.L. and Hickman, J.C. (1995) 'The use of event history analysis to examine insurer insolvencies', The Journal of Risk and Insurance 62(1): 94-110.

Klein, R. (2009) 'The future of financial monitoring of insurance companies in the U.S', Journal of Insurance Regulation 28(1): 73-78.

Klein, R. and Barth, M. (1995) 'Solvency monitoring in the twenty-first century', Journal of Insurance Regulation 13(3): 256-302. 
Koeke, J. (2002) 'Determinants of acquisition and failure: Evidence from corporate Germany', Structural Change and Economic Dynamics 13(4): 457-484.

Larson, S. (1998) 'Weathering the storm: Using exposure and financial variables to predict insurance company failure after Hurricane Andrew', Journal of Insurance Regulation 17(1): 64-85.

Lau, A. (1987) 'A five-state financial distress prediction model', Journal of Accounting Research 25(1): 127-138.

Leadbetter, D. and Dibra, S. (2008) 'Why insurers fail: The dynamics of property and casualty insurance insolvency in Canada', The Geneva Papers on Risk and Insurance - Issues and Practice 33(3): 464-488.

LeClere, M.J. (2000) 'The occurrence and timing of events: Survival analysis applied to the study of financial distress', Journal of Accounting Literature 19: 158-189.

Lee, S., Mayers, D. and Smith, C. (1997) 'Guaranty funds and risk-taking: Evidence from the insurance industry', Journal of Financial Economics 44(1): 3-24.

Lee, S.H. and Urrutia, J.L. (1996) 'Analysis and prediction of insolvency in the property-liability insurance industry: A comparison of logit and hazard models', The Journal of Risk and Insurance 63(1): 121-130.

Liskov, R and Mros, D. (2009) 'What happens when your financial guaranty insurer goes "bust"?', from http://www.chadbourne.com/events/2009/financialguaranty/, accessed 15 August 2012.

Liu, J. (2004) 'Macroeconomic determinants of corporate failures: Evidence from the UK', Applied Economics 36(9): 939-945.

Löffler, G. and Posch, P. (2007) Credit risk modeling using Excel and VBA, West Sussex: Wiley Finance.

Mayer, S., Verdesca, J., Schmidt, S., Lee, J. and Napier, J. (2011) Alphabet Soup of Receivership and Similar Proceedings, paper presented at $30^{\text {th }}$ Annual Jay L. Westbrook Bankruptcy Conference, School of Law, The University of Texas.

Murphy, A.H. (1973) 'A new vector partition of the probability score', Journal of Applied Meteorology and Climatology 12(4): 595-600.

Murphy, A.H. and Winkler, R. (1977) 'Reliability of subjective probability forecasts of precipitation and temperature', Applied Statistics 26(1): 41-47.

NAIC (2009) Alternative mechanisms for troubled companies, National Association of Insurance Commissioners (NAIC) White Paper, from www.litigationconferences.com/wp-content/uploads/2010/01/ 05_Alternative-Mechanisms-White-Paper-Draft-clean.pdf, accessed 15 August 2012.

Partington, G., Russel, P., Stevenson, M. and Torbey, V. (2001) 'Predicting return outcomes to shareholders from companies entering Chapter 11 bankruptcy', Managerial Finance 27(4): 78-96.

Pérez, S.E., Sanchis-Llopis, A. and Sanchis-Llopis, J.A. (2010) 'A competing risks analysis of firms' exit', Empirical Economics 38(2): 281-304.

Pottier, S.W. and Sommer, D.W. (1999) 'Property-liability insurer financial strength ratings: Differences across rating agencies', The Journal of Risk and Insurance 66(4): 621-642.

Prantl, S. (2003) Bankruptcy and Voluntary Liquidation: Evidence for New Firms in East and West Germany after Unification, ZEW Discussion paper No. 03-72, Centre for European Economic Research, Mannheim: ZEW.

Rösch, D. and Scheule, H. (2005) 'A multi-factor approach for systematic default and recovery risk', Journal of Fixed Income 15(2): 63-75.

Samuelson, W. and Rosenthal, L. (1986) 'Price movements as indicators of tender offer success', The Journal of Finance 41(2): 481-499.

Sander, F. (1963) 'On subjective probability forecasting', Journal of Applied Meteorology and Climatology 2(2): 191-201.

Schary, M.A. (1991) 'The probability of exit', The Rand Journal of Economics 22(3): 339-353.

Sharpe, I. and Stadnik, A. (2007) 'Financial distress in Australian general insurers', The Journal of Risk and Insurance 74(2): 377-399.

Shumway, T. (2001) 'Forecasting bankruptcy more accurately: A simple hazard model', The Journal of Business 74(1): 101-124.

Trieschmann, J.S. and Pinches, G.E. (1973) 'A multivariate model for predicting financially distressed P-L insurers', The Journal of Risk and Insurance 40(3): 327-338.

Vacca, D. (2007) 'Exiting the market and receivership', from www.slideserve.com/raanan/exiting-the-marketand-receivership, accessed 15 August 2012.

Whalen, G. (1991) 'A proportional hazard model of bank failure: An examination of its usefulness as an early warning tool', Economic Review, Federal Reserve Bank of Cleveland (first quarter), pp. 21-31.

Wheelock, D.C. and Wilson, P.W. (2000) 'Why do banks disappear? The determinants of U.S. bank failures and acquisitions', The Review of Economics and Statistics 82(1): 127-138. 
Winkler, R.L., Muñoz, J., Cervera, J.L., Bernardo, J.M., Blattenberger, G., Kadane, J.B., Lindley, D.V., Murphy, A.H., Oliver, O.M. and Rios-Insua, D. (1996) 'Scoring rules and the evaluation of probabilities', Test 5(1): 1-60.

Yao, J., Partington, G. and Stevenson, M. (2005) 'Run length and the predictability of stock price reversals', Accounting \& Finance 45(4): 653-671.

Yates, J. (1982) 'External correspondence: Decompositions of the mean probability score', Organizational Behavior and Human Performance 30(1): 132-156.

\section{About the Author}

Huong Dang is a lecturer in Finance at the University of Canterbury. She received her MBA and MSc in Management from the University of Arizona, and her PhD in Economics from the University of Sydney. She is a CFA charterholderand a certified FRM. Her current research interests include financial institutions, financial distress, credit ratings, and scoring rules.

\section{Appendix}

\section{Model estimation and forecast assessment}

As indicated in section "Methods", the type-specific dynamic Cox's hazard models for insurer $m$ can be expressed as:

$$
h_{s, m}(t, Z, Z(t))=h_{s(0)}(t) \exp \left[Z_{j}^{m} \beta_{j}+Z_{p}^{m}(t) \beta_{p}\right]
$$

The estimation procedure makes use of risk sets, which are composed of all the firms that are at risk of an event at time $t$. In the process of estimating the model, a new risk set is formed at each time $t$ when an event of interest occurs. Firms leave the risk set once they experience an event of interest, or when they are censored.

The vectors of the estimated coefficients $\hat{\beta}_{p}$ and $\hat{\beta}_{j}$ can be obtained by maximising the partial likelihood $P L_{s}$, which is the product of the likelihoods, for all insurers $m$ that experienced insolvency outcome $s$, across all event times $t_{m}$ observed in the estimation sample:

$$
P L_{s}=\prod_{m=1}^{n_{s}}\left[\frac{\exp \left(\beta_{j} Z_{j}^{m}+\beta_{p} Z_{p}^{m}\left(t_{m}\right)\right)}{\sum_{i \in R\left(t_{m}, s\right)} \exp \left(\beta_{j} Z_{j}^{i}+\beta_{p} Z_{p}^{i}\left(t_{m}\right)\right)}\right],
$$

where $n_{s}$ is the number of events of type $s$ observed in the estimation sample.

With time-varying covariates $Z_{p}(t)$, the proportionality assumption of the conventional Cox's hazard $\operatorname{model}^{7}$ does not hold. Thus, it is not possible to extract the baseline hazard $h_{s(0)}(t)$ from the Cox's regression results. This study applies a method proposed by Andersen ${ }^{65}$ and modifies Chen et al.'s ${ }^{66}$ SAS codes to estimate

\footnotetext{
65 Andersen (1992).

${ }^{66}$ Chen et al. (2005).
} 
the integrated baseline hazard and thereby overcome the computational challenges. Given the vectors of the estimated coefficients $\hat{\beta}_{p}$ and $\hat{\beta}_{j}$ obtained from Eq. (A.1), the integrated baseline hazard function $H_{s(0)}(t)$ can be estimated as:

$$
\hat{H}_{s(0)}(t)=\sum_{t_{m} \leqslant t} \frac{D_{m, s}}{\sum_{i \in R\left(t_{m}, s\right)} \exp \left(\hat{\beta}_{j} Z_{j}^{i}+\hat{\beta}_{p} Z_{p}^{i}\left(t_{m}\right)\right)},
$$

where $D_{m, s}$ is an indicator for whether an event type $s$ occurred to firm $m$ at time $t_{m}$ within the interval $[0, t]$.

The integrated baseline hazard function $H_{s(0)}(t)$ can also be estimated as a step function discontinued at event time $t_{m}{ }^{66}$

$$
H_{s(0)}(t)=\sum_{t_{m} \in t}\left[h_{s(0)}\left(t_{m-1}\right)\left(t_{m}-t_{m-1}\right)\right]
$$

The estimated baseline hazard function at time $t, \hat{h}_{s(0)}(t)$, can then be derived from Eqs (A.2) and (A.3).

The estimated hazard of holdout firm $q$ for an event type $s$ at time $t$ can be estimated using firm $q$ 's actual covariate vector $Z_{j}^{q}$ and $Z_{p}^{q}(t)$, the estimated baseline hazard function $\hat{h}_{s(0)}(t)$, and the estimated coefficient vector $\hat{\beta}_{p}$ and $\hat{\beta}_{j}$ :

$$
\hat{h}_{s, q}(t, Z, Z(t))=\hat{h}_{s(0)}(t) \exp \left[Z_{j}^{q} \hat{\beta}_{j}+Z_{p}^{q}(t) \hat{\beta}_{p}\right]
$$

The predicted survival function of holdout firm $q$ at time $t$ can be estimated as:

$$
\hat{S}_{s, q}(t, Z, Z(t))=\exp -\left[\sum \hat{h}_{s, q}(t, Z, Z(t))\right]
$$

The Brier score ${ }^{15}$ is used to assess the predictive accuracy of probability survival estimates formed in Eq. (A.5). The Brier score at time $t, B_{t, s}$, is defined as:

$$
B_{t, s}=\frac{\left.\sum_{q=1}^{N_{t}}\left[\hat{S}_{s, q}(t, Z, Z(t))-a_{s, q}\right)^{2}\right]}{N_{t}},
$$

where $\hat{S}_{s, q}(t, Z, Z(t))$, obtained from Eq. (A.5), is the probability forecast that holdout firm $q$ will survive from the insolvency type $s$ at forecast time $t . a_{s, q}$ is the known outcome survival state of holdout firm $q$. If holdout firm $q$ survives from the insolvency type $s, a_{s, q}=1$, and if holdout firm $q$ experienced the event of type $s, a_{s, q}=0$. $N_{t}$ is the number of insurers in the holdout sample at forecast time $t$, which is also the number of estimates at forecast time $t$. 